\title{
AN INVESTIGATION OF GAS SEPARATION MEMBRANES FOR REDUCTION OF THERMAL TREATMENT EMISSIONS
}

\author{
D. M. Stull
}

B. W. Logsdon, Ph.D.

J. J. Pellegrino, Ph.D.*

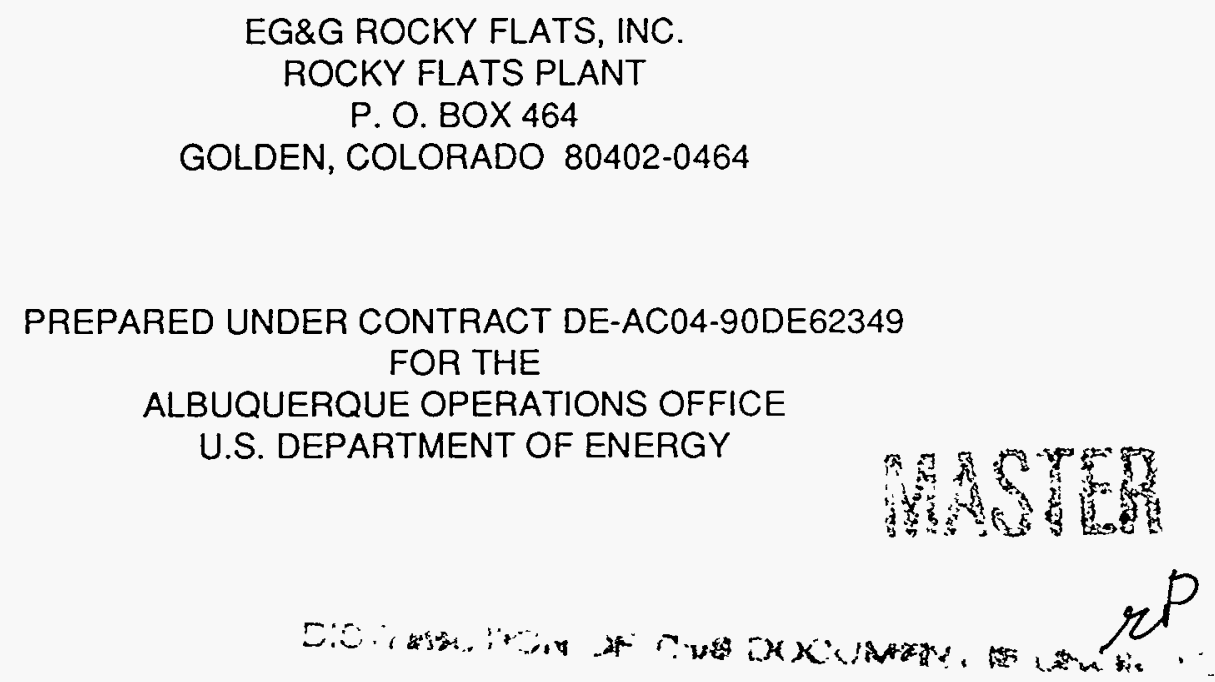


RFP-4641 


\section{DISCLAIMER}

This report was prepared as an account of work sponsored by an agency of the United States Government. Neither the United States Government nor any agency thereof, nor any of their employees, make any warranty, express or implied, or assumes any legal liability or responsibility for the accuracy, completeness, or usefulness of any information, apparatus, product, or process disclosed, or represents that its use would not infringe privately owned rights. Reference herein to any specific commercial product, process, or service by trade name, trademark, manufacturer, or otherwise does not necessarily constitute or imply its endorsement, recommendation, or favoring by the United States Government or any agency thereof. The views and opinions of authors expressed herein do not necessarily state or reflect those of the United States Government or any agency thereof. 


\section{DISCLAIMER}

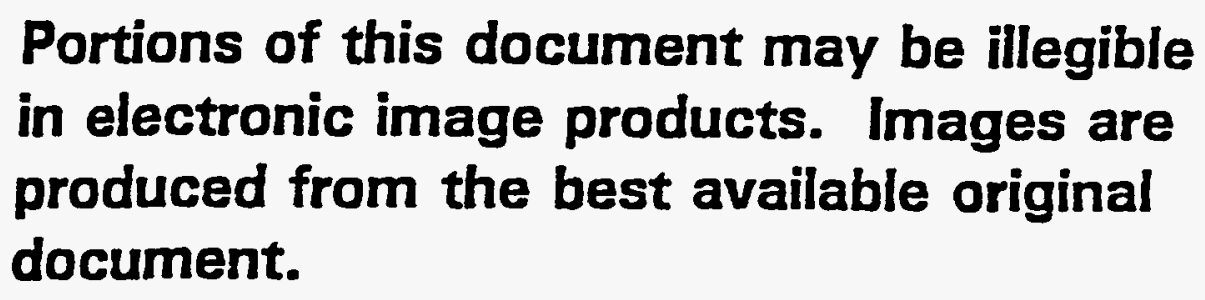




\section{CONTENTS}

ABSTRACT $\ldots \ldots \ldots \ldots \ldots \ldots \ldots \ldots \ldots$

EXECUTIVE SUMMARY $\ldots \ldots \ldots \ldots \ldots \ldots$

INTRODUCTION $\ldots \ldots \ldots \ldots \ldots \ldots \ldots \ldots \ldots \ldots \ldots \ldots \ldots$

GAS PERMEATION THEORY . . . . . . . . . . 4

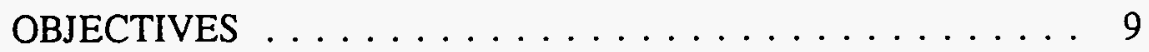

EXPERIMENTAL WORK ............... 9

Single Component Study $-\mathrm{CO}_{2}, \mathrm{O}_{2}, \mathrm{~N}_{2} \ldots \ldots \ldots \ldots \ldots$

Multicomponent Study $-\mathrm{CO}_{2}, \mathrm{O}_{2}, \mathrm{~N}_{2} \ldots \ldots \ldots \ldots \ldots$

Multicomponent Study $-\mathrm{CO}_{2}, \mathrm{O}_{2}, \mathrm{~N}_{2}, \mathrm{nC}_{1}-\mathrm{C}_{3} \ldots \ldots \ldots \ldots$

Liquid Organic Permeation Study . . . . . . . . . 10

Membrane Degradation Study . . . . . . . . . . . . . 12

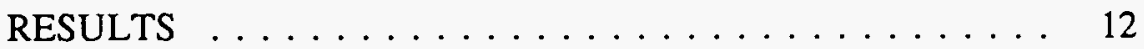

Single Component Study $-\mathrm{CO}_{2}, \mathrm{O}_{2}, \mathrm{~N}_{2} \ldots \ldots \ldots \ldots \ldots$

Multicomponent Study $-\mathrm{CO}_{2}, \mathrm{O}_{2}, \mathrm{~N}_{2} \ldots \ldots \ldots \ldots \ldots \ldots$

Multicomponent Studies - $\mathrm{CO}_{2}, \mathrm{O}_{2}, \mathrm{~N}_{2}, \mathrm{nC}_{1}-\mathrm{C}_{3} \ldots \ldots \ldots 15$

Liquid Organic Permeation Study . . . . . . . . . . 17

Membrane Degradation Study . . . . . . . . . . . . . 18

Simulation Results . . . . . . . . . . . . . . . . 21

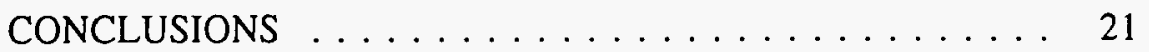

RECOMMENDATIONS ................ 23

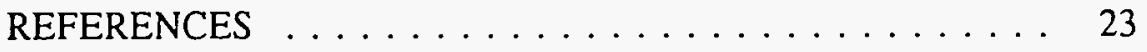

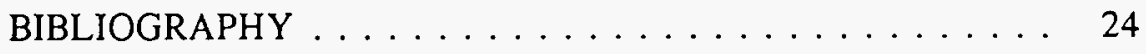

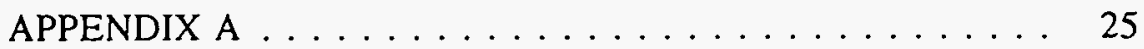


RFP-4641 


\title{
AN INVESTIGATION OF GAS SEPARATION MEMBRANES FOR REDUCTION OF THERMAL TREATMENT EMISSIONS
}

\author{
D. M. Stull, B. W. Logsdon, Ph.D., and \\ J. J. Pellegrino, Ph.D.*
}

\begin{abstract}
Gas permeable membranes were evaluated for possible use as air pollution control devices on a fluidized bed catalytic incineration unit. The unit is a candidate technology for treatment of certain mixed hazardous and radioactive wastes at the Rocky Flats Plant. Cellulose acetate and polyimide membranes were tested to determine the permeance of typical off-gas components such as carbon dioxide, nitrogen, and oxygen. Multicomponent permeation studies included gas mixtures containing light hydrocarbons. Experiments were also conducted to discover information about potential membrane degradation in the presence of organic compounds.
\end{abstract}

\section{EXECUTIVE SUMMARY}

This report summarizes a study of the gas separation properties of a variety of commercially available membranes. Membranes are used to separate various gases because different gases pass through the membranes at different rates. Studies were conducted to determine if membranes could release ordinary products of combustion (carbon dioxide and water) while retaining undesirable chemicals and particulates in the system.

This work is an outgrowth of off-gas studies for the Fluidized Bed Unit (FBU), which is currently under development at The Rocky Flats Plant (RFP) as a candidate technology for treatment of mixed hazardous and radioactive waste. In addition to conventional off-gas treatment, a proposal was made to study a hold-test-release (H-T-R) option.

- National Institute of Standards and Technology (NIST)
The H-T-R design was to be a closed, recirculating system that would capture the products of complete combustion (water and carbon dioxide), store them in the liquid state, and release them only after testing verified that release was safe. Gas separation membranes were initially studied as a method for removing non-condensible gases (e.g., nitrogen) so they would not continuously build up in the recirculating gas stream. A schematic of the proposed system, using membranes, is shown in Figure 1.

Gases pass through polymeric membranes at different rates. Generally carbon dioxide is much more permeable than oxygen, which is more permeable than nitrogen. The liquefaction stream is thus richer in carbon dioxide, resulting in improved liquefaction efficiency as well as the return of more oxygen to the FBU. An additional advantage of using membrane technology is that it assists in pollution control. Particulates will not pass through the membranes, and other products of incomplete combustion (PICs) permeate the membrane so slowly that most will recirculate to the FBU. After carbon dioxide liquefaction, a small stream of non-condensible gases remains. An additional membrane is used to separate carbon dioxide and oxygen from this stream and return them to the FBU. The remaining nitrogen is held for storage, testing, and eventual release.

A literature search and discussions with experts in the membrane industry were encouraging, but no work had been done on the use of membranes for this application. A contract was issued to the National Institute of Standards and Technology (NIST) to test experimentally the application of membranes for flue gas clean-up. The objectives included the study of the permeabilities of carbon dioxide, oxygen, nitrogen, and selected organic compounds for three commercial membranes. 


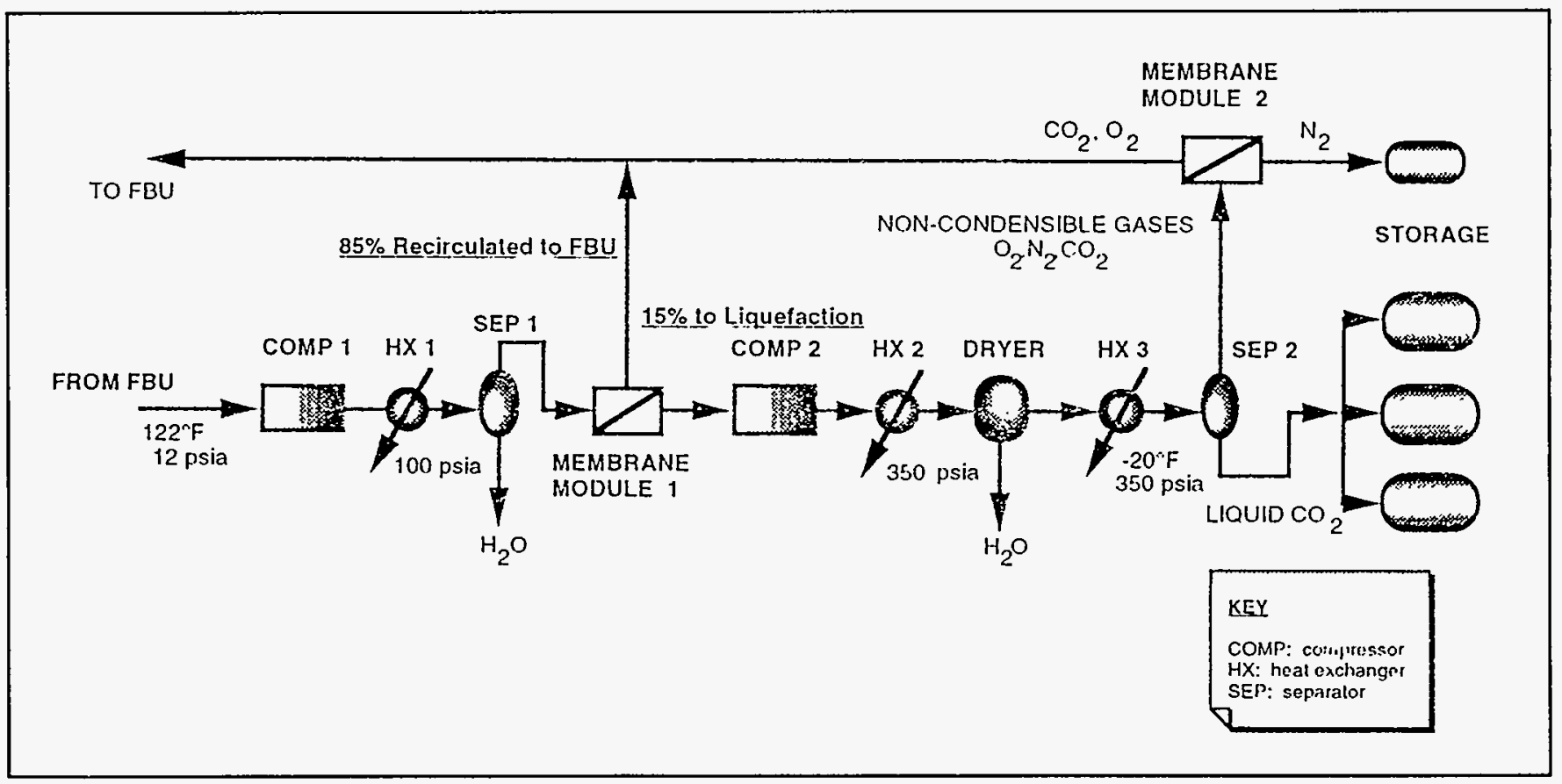

FIGURE 1.Carbon Dioxide Liquefaction for Off-Gas Capture

Tests were conducted for single gases, mixtures of the three gases, and for mixtures of the three gases with certain organic surrogate compounds. Experiments were also designed to study the degradation of the membranes by organic compounds. In late 1992, the H-T-R option was eliminated from the FBU project, and the focus of the research changed somewhat to emphasize the use of membranes for pollution control.

The results of the membrane studies are encouraging. Permeabilities are such that good separation of the gases can be achieved with a reasonably sized membrane module. In fact, computer simulations indicate that incorporation of membranes into the system can reduce hazardous emissions from the FBU by at least two orders of magnitude beyond that achieved by the conventional air pollution control equipment already planned for the FBU. Specific organic compound emissions could be reduced by as much as four orders of magnitude. Figure 2 shows a schematic of an FBU system using a membrane for pollution control in addition to conventional air pollution control equipment.

\section{INTRODUCTION}

Gas permeable membranes are used for a variety of gas separation applications worldwide. Commercially, membranes are used for the production of hydrogen, nitrogen enriched air, and oxygen enriched air, as well as natural gas sweetening and the separation of certain organic chemicals. This report discusses the results of laboratory scale experiments to determine the applicability of using membranes for air pollution control.

This work is an outgrowth of a project at the Rocky Flats Plant (RFP) to develop a fluidized bed catalytic incinerator for treatment of mixed wastes in compliance with the Resource Conservation and Recovery Act (RCRA). As a part of this development, a proposal was made that the off-gas treatment system include a hold-test-release (H-T-R) option in addition to the cyclones and filters already planned. Such a system would capture the off-gas, hold it until analyzed for hazardous compounds, and release it only after the level of hazardous constituents was determined to be below the regulatory limits. One possible 


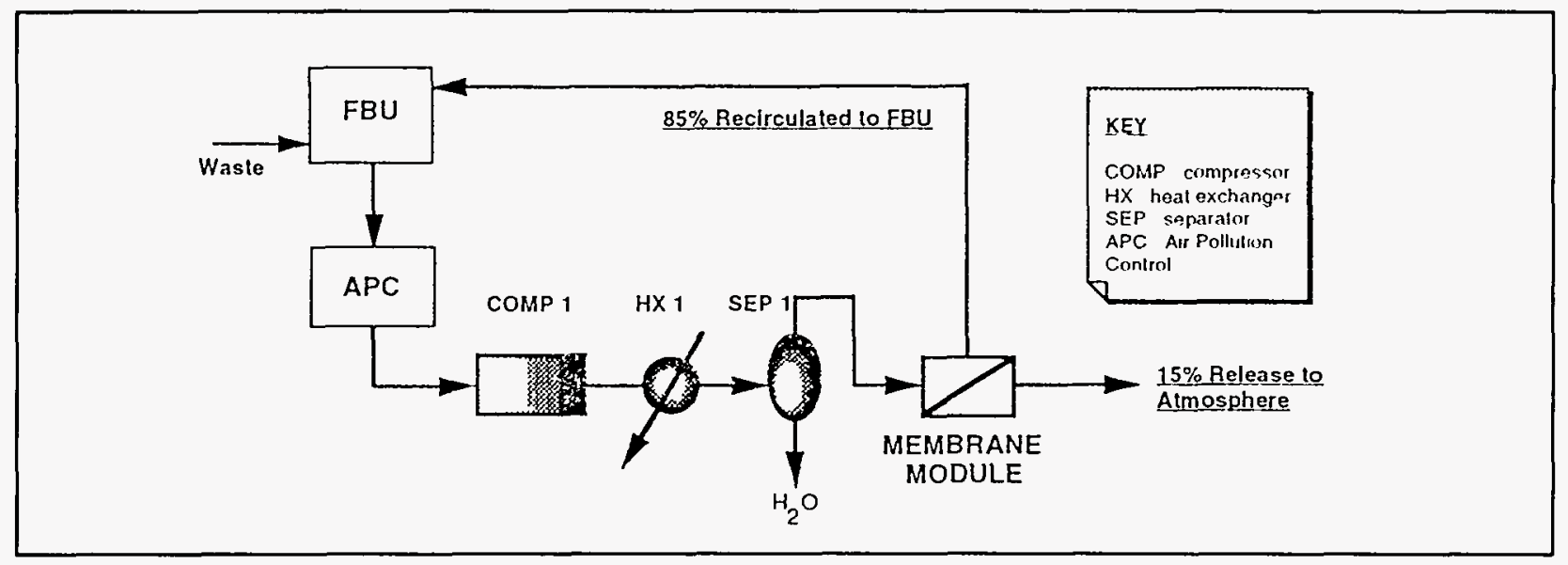

FIGURE 2. Membrane Used as Molecular Filter

design for an H-T-R system was discussed in RFP-4485, "The Liquefaction and Storage of Thermal Treatment Off-Gases."

This H-T-R design would use carbon dioxide $\left(\mathrm{CO}_{2}\right)$ as the fluidizing gas for the fluidized bed unit (FBU), with oxygen $\left(\mathrm{O}_{2}\right)$ being supplied from a dedicated source. The FBU off-gas would consist of fluidizing carbon dioxide, carbon dioxide and water from waste combustion, and excess oxygen. Nitrogen, traces of products of incomplete combustion (PICs), and traces of particulates may also be present. The H-T-R option would remove the water by condensation. A gas stream containing an amount of $\mathrm{CO}_{2}$ equal to that produced by oxidation would be diverted for liquefaction. The remainder of the off-gas would recirculate to the FBU.

One of the technical problems to be solved was that of removing non-condensible gases such as nitrogen $\left(\mathrm{N}_{2}\right)$. Failure to remove these gases results in their gradual buildup in the system and subsequent increased difficulty in $\mathrm{CO}_{2}$ liquefaction. Membrane technology was suggested as a promising method for dealing with this problem. The RFP report recommended that "the use of membrane technology should be investigated further as a means of removing $\mathrm{N}_{2}$ and separating $\mathrm{CO}_{2}$ before liquefaction." A schematic of the proposed liquefaction system, including two membrane modules, is shown in Figure 1.
A review of the relevant literature indicated that $\mathrm{CO}_{2}$ rapidly permeates through polymeric membranes. Nitrogen and non-polar organic molecules are, in general, much less permeable. As shown in Figure 1, Membrane Module 1 produces two streams: a liquefaction stream with a higher concentration of $\mathrm{CO}_{2}$ than the feed stream, and a recirculation stream that returns the particulates, most PIC's, heavy metal aerosols, and much of the oxygen and nitrogen to the FBU. After liquefaction, a small stream of non-condensible gases remains. It consists mostly of $\mathrm{CO}_{2}, \mathrm{~N}_{2}$, and $\mathrm{O}_{2}$, but in different proportions. Membrane Module 2 separates most of the $\mathrm{CO}_{2}$ and $\mathrm{O}_{2}$ for recirculation to the FBU. A small stream rich in $\mathrm{N}_{2}$ remains and is compressed, stored, tested, and released. Enough $\mathrm{N}_{2}$ could be removed in this manner to allow the system to achieve and maintain a small steady state concentration of $\mathrm{N}_{2}$ that could be compensated for in design calculations. In addition to concentrating $\mathrm{CO}_{2}$ and $\mathrm{N}_{2}$, membranes offer the benefit of molecular filtration so that undesirable substances, such as radioactive and toxic combustion byproducts, are retained in the system and returned to the FBU for destruction. This molecular filtration would improve pollution control.

In September 1992 a peer review panel examined the FBU off-gas system and determined that the H-T-R option was unnecessarily complex, and that the perception of increased safety was incorrect. 
The report of the panel is in Appendix A. The panel also questioned the ability to obtain representative samples from the stored carbon dioxide. The H-T-R option was discontinued, but the study of membrane use in pollution control proceeded. The investigation focus shifted somewhat so that information on the permeabilities of organic compounds became as important as collecting information on the permeabilities of $\mathrm{CO}_{2}, \mathrm{O}_{2}$, and $\mathrm{N}_{2}$. Figure 2 shows a schematic of the FBU with a membrane added to the conventional air pollution control system.

Despite the promise of off-gas separation membranes, uncertainties about their feasibility remained; therefore, a project was initiated to address these uncertainties through literature study and experimental work. Among the topics to be investigated were (1) selection of membrane materials, (2) adequacy of $\mathrm{CO}_{2}$ and $\mathrm{N}_{2}$ separation, (3) permeability of organics through the membrane, (4) permeability of metal aerosols through the membrane, and (5) durability of the membranes under normal and upset operating conditions.

The literature offered little information on the use of membranes for flue gas clean-up. Little or no investigation of membranes has been conducted for use in this specific application. Therefore, the literature search was expanded to related areas, uncovering the fact that most commercial applications involving the separation of carbon dioxide and organic compounds are found in the oil and gas industry. One application was the use of gas permeable membranes in oil field tertiary recovery operations. An article by Dinello, et. al., discussed the use of polysulfone membranes for separating $\mathrm{CO}_{2}$ from a gas stream containing significant quantities of hydrocarbons. ${ }^{2}$ The authors reported that the membranes were robust enough to withstand several months of continual, unattended use under oil field conditions. This report indicated that membranes might be durable enough to withstand an upset condition in the FBU when the concentration of contaminants in the off-gas would be highest. Similar systems are currently in use utilizing cellulose acetate mem- branes. In addition, cellulose acetate membranes are also used in the removal of carbon dioxide from natural gas (methane).

Much of the literature is devoted to the development of new polymers for use as membranes. Polymer chemists are learning how to alter the structure of polymer chains to tailor membranes for specific applications. Various polyaramide compounds, including polyimides, have been developed which exhibit wide ranges of permeabilities for various species. Applications include the carbon dioxide/methane separation discussed previously.

The literature review was encouraging but not conclusive. Several experts in the field, including research and development personnel with some of the manufacturers, were confident that the proposed application was feasible. A more definitive answer would require experimental testing of some membranes.

A contract was issued to the National Institute of Standards and Technology (NIST) in Boulder, Colorado, to test experimentally the application of membranes for flue-gas clean-up. This contract included laboratory scale testing of gas permeable membranes with surrogate flue-gas components. NIST was selected because of the expertise of its staff, the availability of the proper test equipment, and its proximity to RFP. The actual experiments were performed by both NIST and RFP personnel. This paper will discuss the results of those experiments.

\section{GAS PERMEATION THEORY}

The membranes used for this study are thin polymeric barriers that preferentially allow certain gases to pass through. The mechanism by which this occurs is a combination of solution and diffusion. A gas passing through a membrane must first dissolve in one side of the membrane, diffuse through the membrane material, and effervesce from the other side of the membrane. The gas that passes through the membrane is 
called the permeate, and the remainder is called the retentate. Separation of gases occurs because each gas dissolves and diffuses at a different rate. For the types of membranes under consideration for this project, polar molecules such as carbon dioxide and water dissolve most easily, and smaller molecules diffuse more readily through the polymer matrix. Particulates, including radioactive metallic aerosols, have very low solubility and virtually no diffusivity in the membrane, effectively preventing the particulates from permeating the membrane.

Permeability is the term used to describe the rate at which a gas passes through a membrane. Mathematically, both solubility and diffusion coefficients are included:

$$
P_{i}=S_{i} D_{i}
$$

$\mathrm{P}_{i}=$ permeability of component $i$

$S_{i}=$ solubility coefficient of component $i$

$\mathrm{D}_{i}=$ diffusion coefficient of component $i$

The solubility coefficient turns out to be a Henry's Law constant. Henry's Law states that the concentration of a gas in a substance (such as water or a membrane) is proportional to the partial pressure of the gas at the surface:

$$
C_{i}=K_{H} p_{i}
$$

$\mathrm{C}_{i}=$ concentration of gas $i$ in the membrane

$\mathrm{K}_{\mathrm{H}}=$ Henry's Law constant

$\mathrm{p}_{i}=$ partial pressure of gas $i$

Other mechanisms have been described that contribute to the total solubility, but only Henry's Law will be discussed here.

Diffusion through the membrane is described by Fick's First Law which states that the rate of diffusion of a gas through a membrane is proportional to the concentration gradient of the gas in the membrane. This rate, called the flux, is the volume of gas diffusing through a membrane of a given area for a given amount of time:

$$
J_{i}=-D_{i}\left(\frac{d c_{i}}{d x}\right)
$$

$\mathrm{J}_{i}=$ flux through the membrane (volume/time/area)

$\mathrm{D}_{i}=$ diffusion coefficient

$c_{i}=$ concentration at any point in the membrane

$x=$ distance from the surface to that point in the membrane

Thus, Henry's Law describes the concentration of a gas in the membrane, and Fick's Law describes the rate of transport through the membrane. Either solubility or diffusion can limit the over-all flux. Solubility and diffusion coefficients are important to polymer chemists developing membranes, but engineers prefer equations expressed in readily measurable terms. By combining the above equations, a more useful expression for flux is found:

$$
J_{i}=\frac{V_{i}}{A}=\frac{P_{i} \Delta p_{i}}{l}
$$

$$
\begin{aligned}
\mathrm{J}_{i}= & \text { flux through the membrane } \\
& \text { (volume/time/area) } \\
\mathrm{V}_{i}= & \text { volumetric flow rate } \\
\mathrm{A}= & \text { mass transfer area of the membrane } \\
\mathrm{P}_{i}= & \text { permeability of the membrane } \\
\Delta \mathrm{p}_{i}= & \text { difference in partial pressure across } \\
& \text { membrane } \\
\mathrm{l}= & \text { thickness of membrane }
\end{aligned}
$$

This equation is the basis for process design calculations. The design engineer usually desires to optimize the total volumetric flow rate $\left(\mathrm{V}_{i}\right)$. Besides choosing a different membrane, the only options available to the design engineer for optimization are the mass transfer area (A) and the difference in partial pressure $\left(\Delta \mathrm{p}_{i}\right)$. Most commercial processes utilize high pressures [ $>7 \mathrm{MPa}$ (1000 psi)], which decrease the membrane area required to achieve a specified permeate flow rate. Generally for a given pressure, the permeate 
stream purity is controlled by the surface area. A smaller area results in a relatively purer permeate stream, and a larger area in a relatively purer retentate stream. Also note that a thinner membrane increases the permeate flux.

Rearranging the above equation yields a useful expression for permeability:

$$
P_{i}=\frac{V_{i} l}{\Delta p_{i} A}
$$

$$
\begin{aligned}
\mathrm{P}_{i} & =\text { permeability } \\
\mathrm{V}_{i} & =\text { volumetric flow rate } \\
1 & =\text { thickness of the membrane } \\
\Delta \mathrm{p}_{i} & =\text { difference in pressure across the membrane } \\
\mathrm{A} & =\text { mass transfer area of the membrane }
\end{aligned}
$$

In the laboratory, volumetric flow rate, area, and pressures can be readily measured. For mixtures, these variables are measured for each gas.

Thickness varies between different kinds of membranes, between different batches of the same kind of membrane, and even at different sites on the same membrane. To compensate, the permeability term is often normalized by dividing permeability by the thickness. The result is the permeance which is defined as:

$$
\rho_{i}=\frac{P_{i}}{l}=\frac{V_{i}}{\Delta p_{i} A}
$$

$$
\begin{aligned}
P_{i} & =\text { permeance } \\
\mathrm{P}_{i} & =\text { permeability } \\
\mathrm{l} & =\text { thickness } \\
\mathrm{V}_{i} & =\text { volumetric flow rate } \\
\Delta \mathrm{p}_{i} & =\text { difference in partial pressure } \\
\mathrm{A} & =\text { mass transfer area of the membrane }
\end{aligned}
$$

Permeance can also be calculated in place of permeability when the thickness of a membrane being tested is unknown.

Since almost any gas or vapor permeates a membrane to some extent, membranes are excellent concentrators. Membrane separation systems are designed to take advantage of the difference in permeation rates for the gases being separated. A convenient way to express the relative permeabilities of any two gases is the selectivity or separation factor, which is the ratio of the permeabilities (or permeances) of the two gases:

$$
\alpha_{i j}=\frac{P_{i}}{P_{j}}
$$

$\alpha_{i j}=$ selectivity of components $i$ and $j$

$\mathrm{P}_{i}=$ permeability (or permeance) of species $i$

$\mathrm{P}_{j}=$ permeability (or permeance) of species $j$

Membranes with high selectivities are desirable because they offer greater separation of the components in a gas mixture. Separation factors can range from 5 for $\mathrm{O}_{2} / \mathrm{N}_{2}$ to 25 for $\mathrm{CO}_{2} / \mathrm{N}_{2}$ and greater than 200 for $\mathrm{H}_{2} / \mathrm{CH}_{4}$. Selectivity is often more important than permeability because it governs the composition of the permeate and retentate streams. Typically, membranes that exhibit high selectivities also exhibit relatively low permeabilities. Fortunately, low permeability can be compensated for by adjusting the membrane area, the feed pressure, and the permeate pressure, as previously discussed.

Thin membranes are desirable because of their increased fluxes, but thin membranes are mechanically weak and cannot perform at the high pressures typically desired for separation processes. Membranes have been developed with asymmetric structures that exhibit both high permeability and high strength. These membranes consist of a thin layer $(\leq 1.0 \mu \mathrm{m})$ for separation and a thick but porous layer for strength. The layers may or may not be made of the same material. Some processes involve making the layers separately and joining with an adhesive. Other processes produce both layers in a single process. Asymmetric membranes are made in two forms, thin flat films and tiny hollow fibers, both of which are illustrated in Figure 3. 


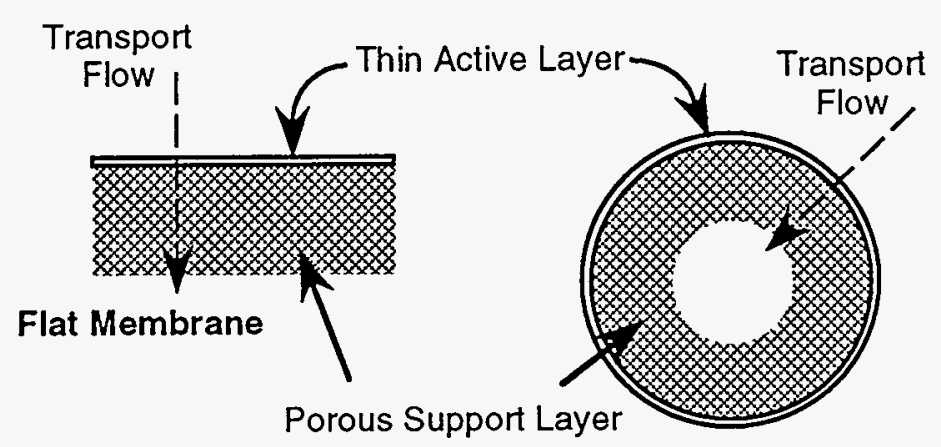

Hollow Fiber Membrane

FIGURE 3. Asymmetric Membrane Structure

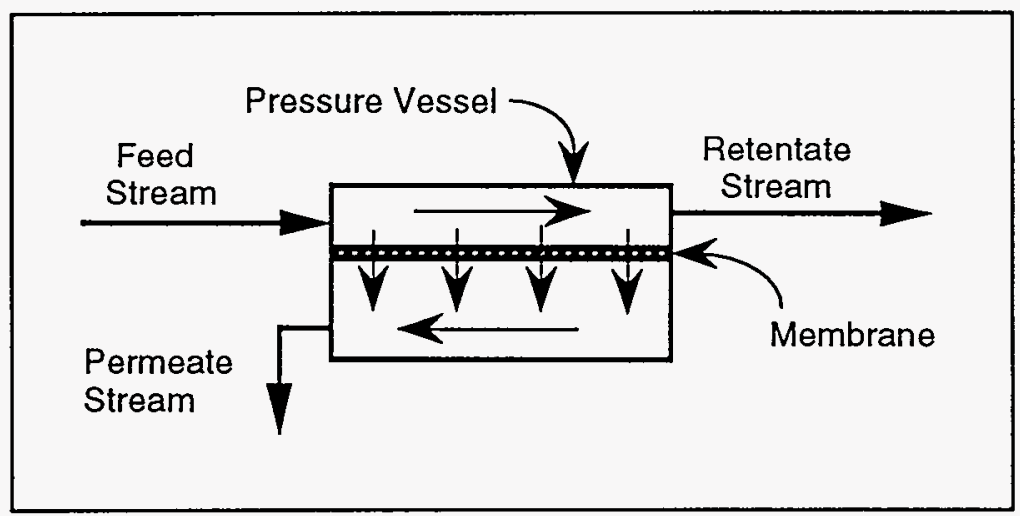

FIGURE 4. Membrane Permeation

Membranes for commercial application are contained in pressure vessels. A simplified module, shown in Figure 4, has one inlet stream and two outlet streams. Some of the feed gas passes through the membrane and exits the module as the permeate stream, and the remainder of the gas exits as the retentate stream. To achieve a maximum $\Delta \mathrm{p}_{i}$, a low partial pressure for component $i$ should be maintained on the permeate side of the membrane. To accomplish this maximum $\Delta \mathrm{p}_{i}$, an inert sweep gas is sometimes introduced to remove the permeate more efficiently. Alternatively, a vacuum may be applied to the permeate outlet to draw off the permeate and maintain very low partial pressures for the permeating species. A counterflow design in which the feed and permeate streams travel in opposite directions is generally the most efficient arrangement and the one that most module designers use.

Although some membrane modules are similar to Figure 4 with a flat piece of membrane inside the pressure vessel, most applications require large surface areas; therefore, the ratio of the membrane surface area to the volume of the pressure vessel needs to be maximized. Spiral wound modules were developed to maximize the surface/volume ratio for flat sheet membranes. These modules consist of membranes rolled up with porous 


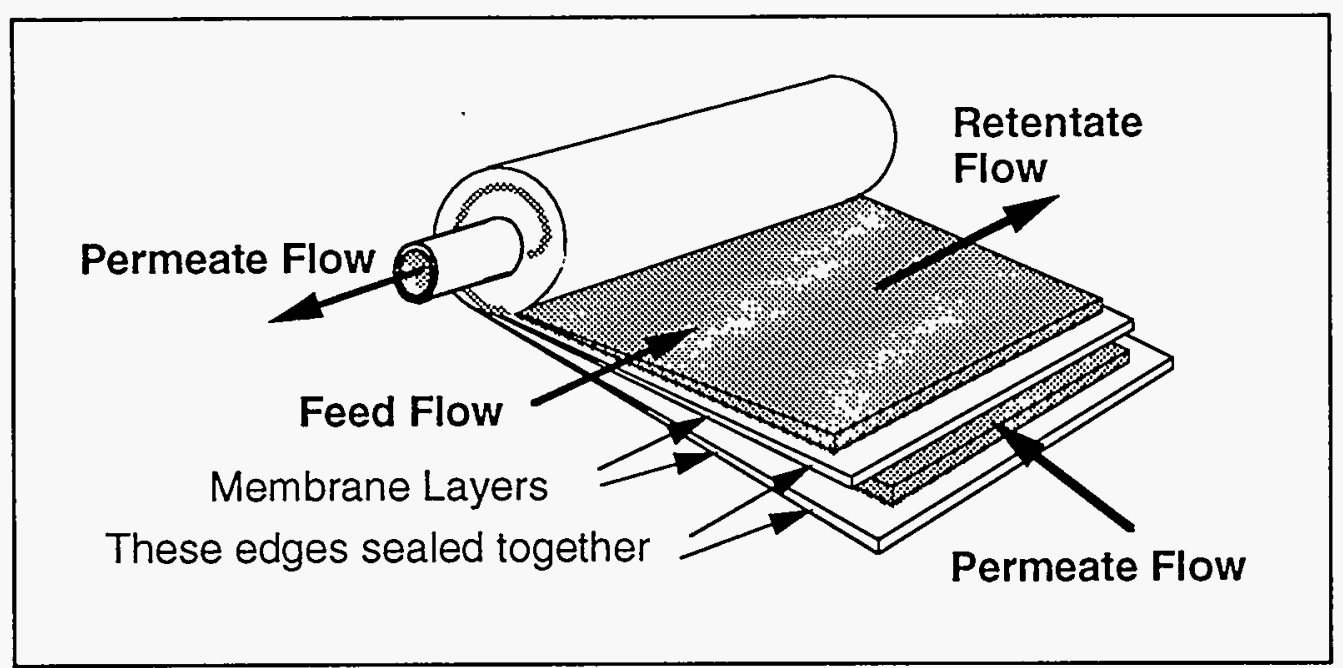

FIGURE 5. Spiral Wound Membrane

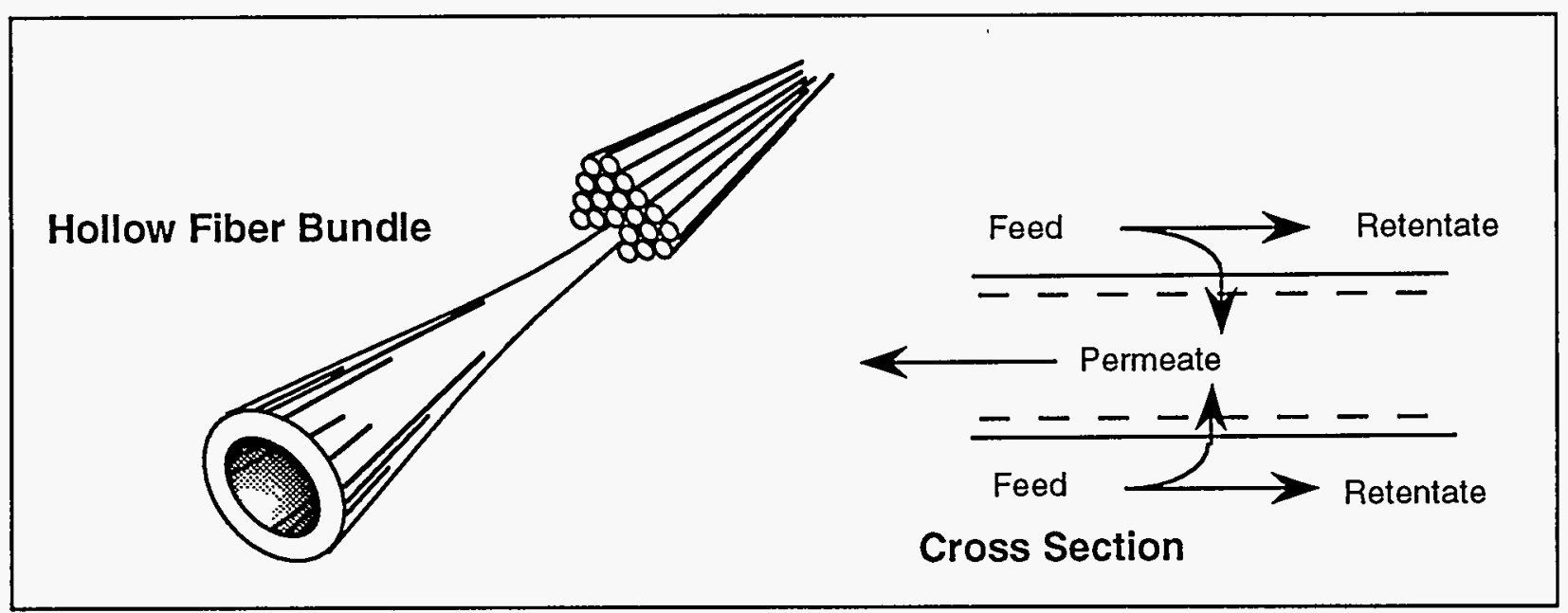

FIGURE 6. Hollow Fiber Membrane

spacers for feed and permeate flow. Figure 5 illustrates a typical spiral wound module. The module includes a central tube sealed on one end and attached to one or more groups of sandwiched layers, each consisting of a layer of porous material between two layers of membrane. Three edges are sealed, and the fourth edge is connected to the tube. On top of these sandwiched layers is another porous layer. The layers are rolled up, similar to a jelly roll, and placed inside a pressure housing with connections for process piping. The feed enters the module and flows through the top porous layer. Some of the gas permeates through the membrane to the sealed porous layer, then moves along that layer to the central tube and out of the module.

Hollow fiber membranes are illustrated in Figure 6. The active separation layer is usually on the outside of the fibers with the permeating gas going from the outside to the inside. Hollow fiber membranes are made by placing bundles of hollow fibers in a cylindrical pressure vessel. Feed gases enter the module and move radially 
into the bundle. Gas permeates through the membrane into the hollow fiber, moves toward an open end, enters a collection chamber, then passes out of the module.

Some membrane materials are subject to interaction with permeating gases. In these cases, the permeating gas alters the structure of the membrane and may change the permeation rates of other feed gases. This phenomenon is known as plasticization. Carbon dioxide is known to plasticize several membrane materials, including cellulose acetate, which is included in this investigation. Membrane plasticization must be accounted for in planning experiments to simulate actual conditions.

\section{OBJECTIVES}

The purpose of this study was to obtain experimental data for use in evaluating the applicability of gas permeable membranes for off-gas cleanup. To accomplish this, the following objectives were defined:

1. Determine the permeabilities of $\mathrm{CO}_{2}, \mathrm{O}_{2}$, and $\mathrm{N}_{2}$, individually, under various pressure conditions.

2. Determine the permeabilities of $\mathrm{CO}_{2}, \mathrm{O}_{2}$, and $\mathrm{N}_{2}$ mixtures under various pressure conditions.

3. Determine the permeabilities of selected gaseous organic compounds in a mixture of $\mathrm{CO}_{2}, \mathrm{O}_{2}$, and $\mathrm{N}_{2}$ under various pressure conditions.

4. Determine the permeabilities of certain organic vapors at various temperatures.

5. Determine if membrane degradation results from exposure to organic compounds.

6. Estimate the emission reductions made possible through the use of a membrane system.

\section{EXPERIMENTAL WORK}

Attempts were made to obtain samples of three types of membranes currently in commercial use for carbon dioxide separations: cellulose acetate, polyimide, and polysulfone. Samples of a cellulose acetate (CA) membrane and a polyimide (PI) membrane were obtained from manufacturers. However, no manufacturer was willing to supply samples of polysulfone. As a replacement, NIST supplied samples of polyperfluorosulfonic acid (PPFSA) which they had been testing for various applications. The PPFSA and the cellulose acetate were in flat sheet form and the polyimide was in hollow fiber form enclosed in small modules. The thickness of the active membrane layer was unknown for the cellulose acetate and polyimide membranes; therefore, data has been reduced to permeances rather than permeabilities.

\section{Single Component Study - $\mathrm{CO}_{2}, \mathrm{O}_{2}, \mathrm{~N}_{2}$}

To meet the first objective, determining the permeabilities of $\mathrm{CO}_{2}, \mathrm{O}_{2}$, and $\mathrm{N}_{2}$, individually, under various pressure conditions, a series of experiments was designed to measure the single component permeance of $\mathrm{CO}_{2}, \mathrm{~N}_{2}$, and $\mathrm{O}_{2}$ for each of the three membranes. These gases were selected because they are expected to constitute the bulk of the FBU off-gas. The experiments were intended to establish the baseline permeances for these gases. The flat membranes were cut into small circles and mounted in a commercial test module. This module or one of the polyimide modules was then installed in the test apparatus shown schematically in Figure 7. One of the gases was fed into the module at a given pressure, and the volume permeating the membrane was measured as a function of time.

PPFSA was tested separately with nitrogen and carbon dioxide over a range of pressures, and the resulting permeances were extremely low. We were informed that PPFSA exhibited much higher 


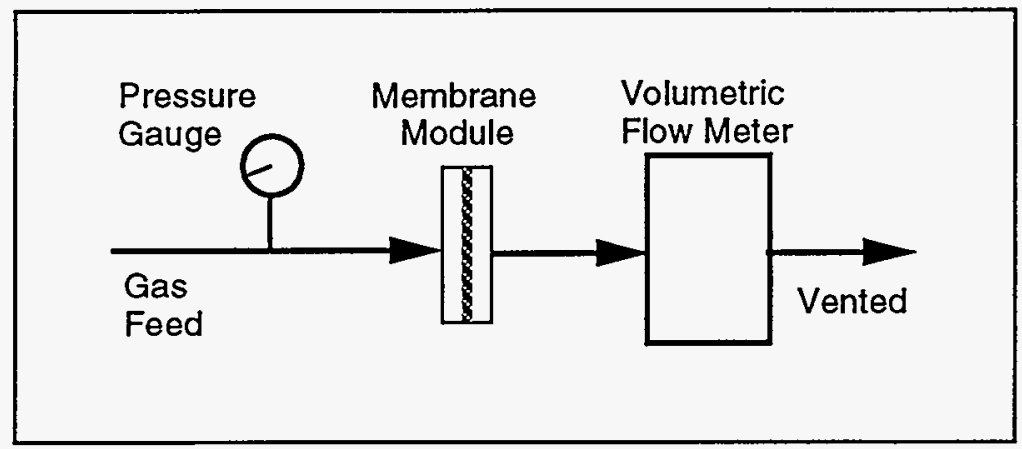

FIGURE 7. Schematic for Single Gas Permeation Experiments

permeabilities if the membrane was saturated with water. Unfortunately, testing under such conditions was beyond the capabilities of our set-up, and PPFSA was eliminated from further study. The celiulose acetate and the polyimide membranes were similarly tested with $\mathrm{CO}_{2}, \mathrm{~N}_{2}$, and $\mathrm{O}_{2}$ and exhibited permeances in the range of what was expected. These volumetric flow measurements were tailored to the permeation rates of the gases and ranged from measuring cubic centimeters over a period of seconds or minutes, to measuring cubic feet over a period of hours. Experiments studying $\mathrm{CO}_{2}$ permeation through $\mathrm{CA}$ were conducted over a period of several days in order to observe the expected plasticization.

\section{Multicomponent Study $-\mathrm{CO}_{2}, \mathrm{O}_{2}, \mathrm{~N}_{2}$}

To meet the second objective, determining the permeabilities of $\mathrm{CO}_{2}, \mathrm{O}_{2}$, and $\mathrm{N}_{2}$ mixtures under various pressure conditions, experiments involving tertiary mixtures of $\mathrm{CO}_{2}, \mathrm{~N}_{2}$, and $\mathrm{O}_{2}$ were devised to find the permeance of each gas in the mixture so that the results could be compared to the single component data. Determining if the phenomenon of membrane plasticization was occurring, and if so, how it would affect the permeabilities of the gases was also necessary. Most importantly, calculating the selectivities based on mixtures similar to those expected from the FBU was necessary. The experiments were performed in a system that expanded on the single gas system described above and is shown schematically in Figure 8 . The desired feed mixture was maintained by three flow control valves, one for each gas. The set-up included a helium sweep gas with a constant flow rate, which was also maintained by a flow control valve. A gas chromatograph was used to measure the permeate and retentate compositions by alternately sampling each stream every 30 minutes over a period of several hours. The experiments were repeated several times, at increasing pressures.

\section{Multicomponent Study - $\mathrm{CO}_{2}, \mathrm{O}_{2}, \mathrm{~N}_{2}, \mathrm{nC}_{1}-\mathrm{C}_{3}$}

The third set of experiments involved finding a permeance for each species in a mixture that included $\mathrm{CO}_{2}, \mathrm{~N}_{2}$, and $\mathrm{O}_{2}$ along with carbon monoxide $(\mathrm{CO})$, hydrogen $\left(\mathrm{H}_{2}\right)$, ethane $\left(\mathrm{C}_{2} \mathrm{H}_{6}\right)$, and propane $\left(\mathrm{C}_{3} \mathrm{H}_{8}\right)$. To produce this mixture, the three flow control valves were used to control $\mathrm{CO}_{2}, \mathrm{O}_{2}$, and a commercially prepared mixture of the other five gases. These experiments were intended to provide information on the permeance of $\mathrm{CO}$, a gas that must always be considered in relation to combustion, and of two hydrocarbons that are gases at the room temperatures. Heavier hydrocarbons, which exist as liquids and solids under normal temperatures and pressures, could not be tested in this flow system because of potential condensation problems.

\section{Liquid Organic Permeation Study}

Because information about the permeation of heavier hydrocarbons, including aromatics, was necessary to meet the final objective, estimating 


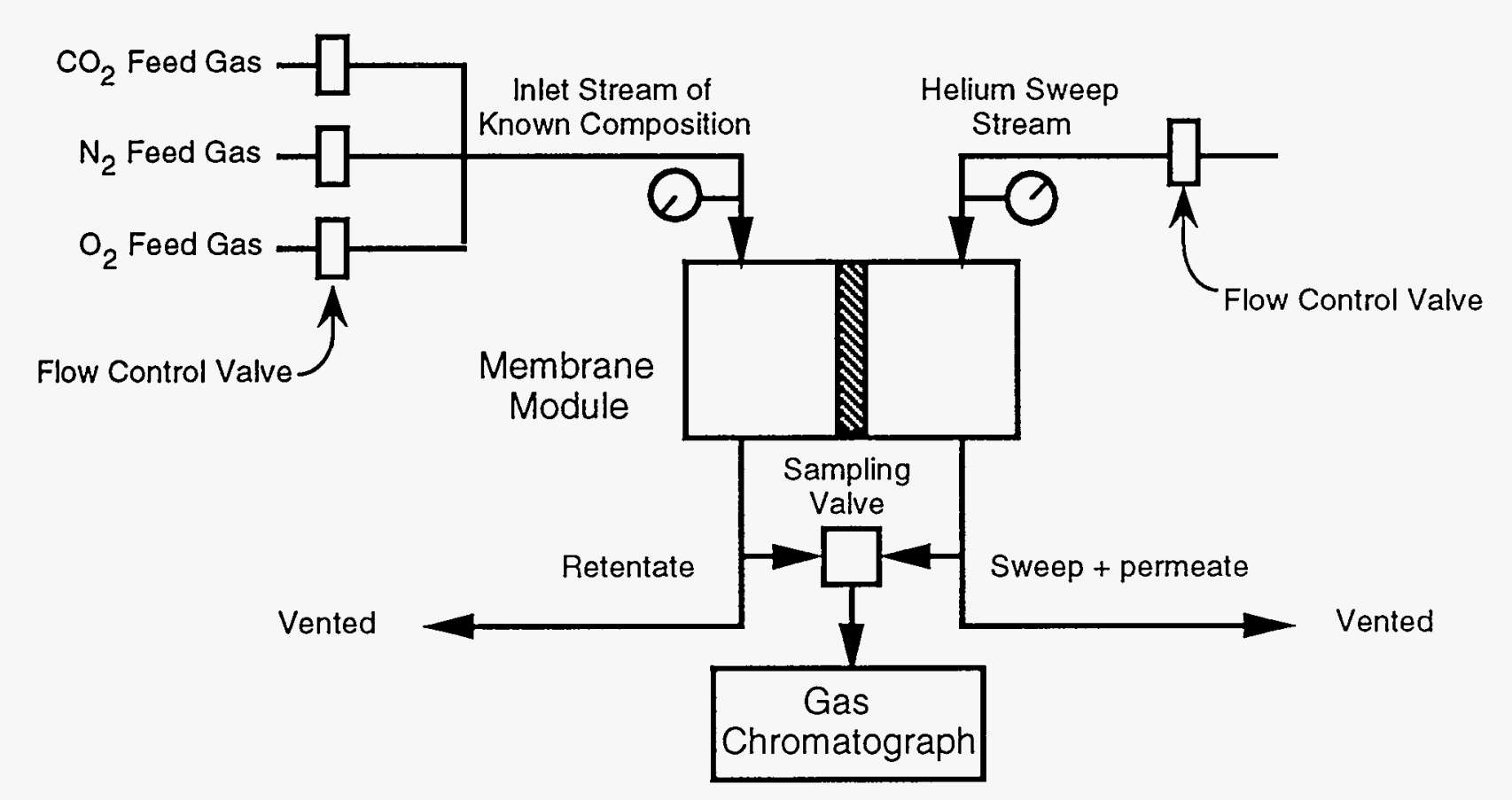

FIGURE 8. Schematic for Gas Mixture Permeation Experiments

the emission reductions made possible through the use of a membrane system, an experiment was devised to determine the permeances of a few selected compounds. A small vial was partially filled with a sample compound, then covered with a small piece of membrane and a screw cap which had an opening of known area in the top (See Figure 9). Permeance can be calculated from the lost weight, the membrane area, and the partial pressure of the liquid at the test temperature. The assembly was weighed and allowed to sit for a period of time at a controlled temperature and then weighed again. The lost weight (if any) represented the amount of the substance that permeated the membrane. Five vials were prepared for each compound, along with five vials with similar caps, but no membranes for comparison. Experiments were conducted at several temperatures to obtain data at more than one partial pressure. Because of the form of the polyimide membrane, this experiment could be performed only on or with the cellulose acetate membrane.
Compounds for these experiments were selected to simulate possible FBU emissions. Several categories of organic compounds were tested, including paraffins, olefins, and aromatics, some in oxygenated or chlorinated forms. One compound, 1,2-dichlorobenzene, was of particular

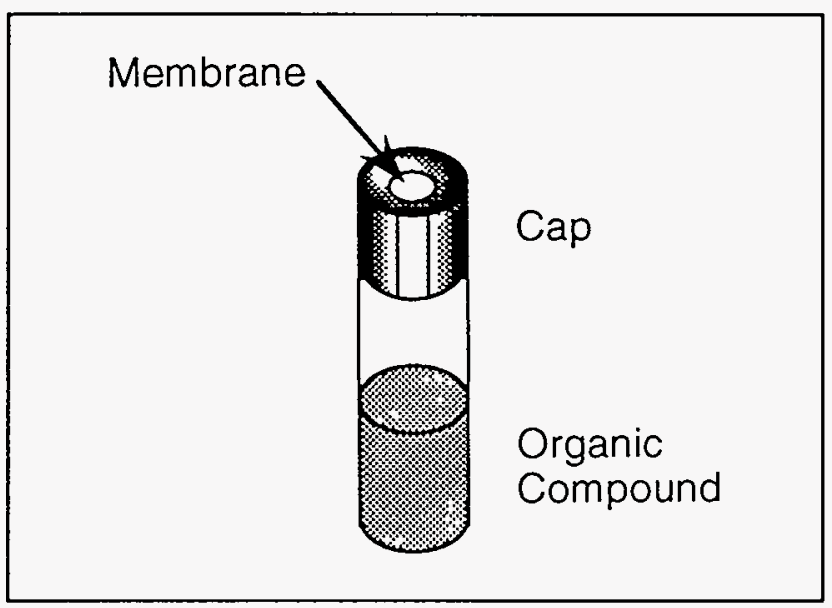

FIGURE 9. Vial Used to Study Permeation of Organic Compounds 
interest because it could be used to approximate three types of compounds of concern: dioxins, dibenzofuran, and polychlorinated biphenyls (PCBs). A 1,2-dichlorobenzene molecule is essentially one-half of a molecule of each of these compounds. If the permeability of the 1,2-dichlorobenzene is low, then extrapolating even lower permeabilities for whole molecules of these compounds is reasonable.

\section{Membrane Degradation Study}

To satisfy objective number five, the determination of membrane degradation resulting from exposure to organic compounds, and to determine whether the membranes might be affected through the interaction with organic contaminants, the membrane degradation experiment was performed.

The compounds selected for this study, listed in the order that the testing was conducted, were 1,2-dichlorobenzene, o-xylene (1,2-dimethylbenzene), benzene, and cyclohexane. To condition a cellulose acetate membrane, a sample of the membrane was placed into an atmosphere saturated with the organic compound at $30^{\circ} \mathrm{C}$ for 24 hours. After conditioning, the membranes were tested in a multicomponent flow apparatus similar to the one previously described. A different gas chromatograph setup was used in an attempt to gain better separation of the various components in the permeate stream. This process was then repeated with a new membrane sample and a 72 hour exposure. The polyimide modules were conditioned by pumping air saturated with the organic compound through the module for similar 24 and 72 hour periods, followed by the testing previously described. Because of the limited number of polyimide modules obtained, after each test the organic compound was vacuum stripped from the polyimide modules and the modules were reused. Unfortunately, the degradation caused by benzene was severe and irreversible, requiring the use of new modules for testing with cyclohexane.

Conditioning the membranes in this manner was intended to approximate the kinds of changes that could occur in a real gas stream where the membrane would be exposed to lower concentrations of organic contaminants, but for longer periods. Unfortunately, this approximation has some limitations. Most of the effects of organics on the membranes are expected to be concentration dependent. A short exposure at high concentrations will result in an effect greater than a low exposure for extended periods and will over-estimate the degradation of the membrane by an unknown amount. Thus, any negative effects of degradation are probably greater than would be observed in actual operation, while a lack of degradation would probably predict a similar lack of degradation in actual operation. These results require confirmation under conditions similar to actual FBU operation.

\section{RESULTS}

\section{Single Component Study - $\mathrm{CO}_{2}, \mathrm{O}_{2}, \mathrm{~N}_{2}$}

The initial purpose of this study was to determine the applicability of membranes for the production of a very pure $\mathrm{CO}_{2}$ stream for liquefaction. The separation of $\mathrm{N}_{2}$ from the $\mathrm{CO}_{2}$ would be essential for liquefaction, and consequently the initial portion of this investigation focused on $\mathrm{CO}_{2} / \mathrm{N}_{2}$ separation. After the elimination of the off-gas capture option for the FBU, the focus switched to separation of organic and inorganic particulates from the $\mathrm{CO}_{2}$ stream. In this application, the separation of $\mathrm{N}_{2}$ from $\mathrm{CO}_{2}$ is important because it could be a major component of the off-gas stream requiring removal. Therefore, high $\mathrm{CO}_{2} / \mathrm{N}_{2}$ separation factors are an indication that $\mathrm{CO}_{2}$ /organic separation factors will also be high.

The results of the single component permeation studies are shown in Figure 10. The cellulose acetate and polyimide membranes are clearly superior to the PPFSA membrane, as they exhibited $\mathrm{CO}_{2}$ permeances an order of magnitude greater than the PPFSA membrane. The permeation of $\mathrm{CO}_{2}$ through the cellulose acetate membrane was about twice that through the polyimide membrane ( 29 vs. $14 \mathrm{moles} / \mathrm{m}^{2}-\mathrm{s}-\mathrm{kPa}$ ), 


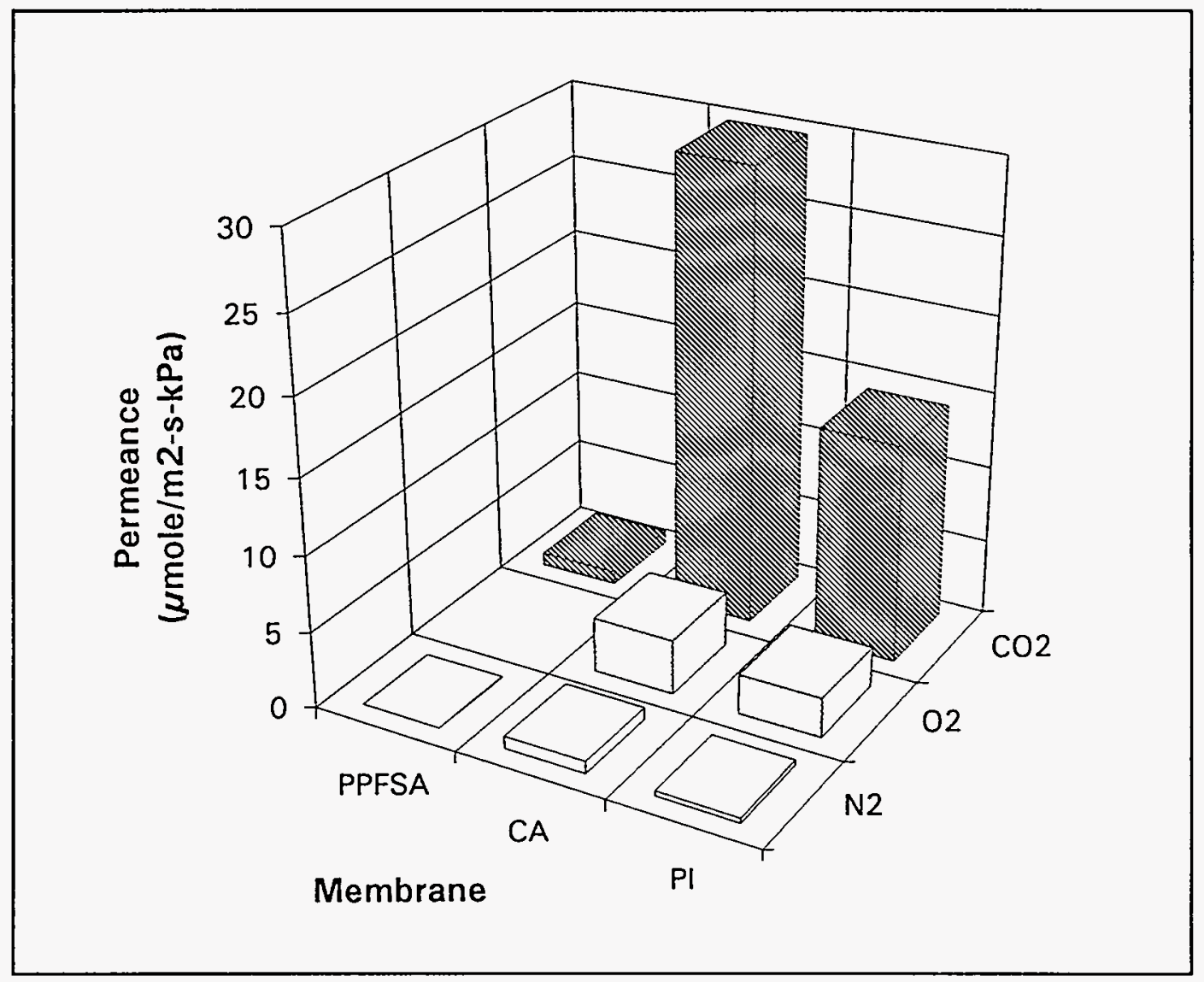

FIGURE 10. Permeance - Single Component

with $\mathrm{N}_{2}$ and $\mathrm{O}_{2}$ permeances being about the same for the two membranes $\left(0.8\right.$ and $3.5 \mathrm{moles} / \mathrm{m}^{2}-\mathrm{s}$ $\mathrm{kPa}$ for cellulose acetate and 0.3 and 2.5 moles/ $\mathrm{m}^{2}-\mathrm{s}-\mathrm{kPa}$ for polyimide respectively). This results in a $\mathrm{CO}_{2} / \mathrm{N}_{2}$ separation factors for both membranes of about 40 and $\mathrm{CO}_{2} / \mathrm{O}_{2}$ separation factors of 8 and 5 respectively for cellulose acetate and PI. Based on these results, cellulose acetate appears to be the material of choice for this separation. The CA membrane exhibited $\mathrm{CO}_{2}$ permeance that changed with time, as shown in Figure 11. This change is evidence that $\mathrm{CO}_{2}$ is plasticizing the cellulose acetate membrane (i.e., interfering with the polymer's crystalline structure and making it more amorphous). This plasticization can affect the permeance of other gases (including organics) as well as that of $\mathrm{CO}_{2}$. The polyimide membrane did not show this effect. Because of the plasticization of CA, better approximations for the permeances of gases through the cellulose acetate membrane must be made under the expected operating pressures of the membrane. To evaluate this permeance, a multicomponent system capable of simultaneously measuring the permeances of all three gases was needed.

\section{Multicomponent Study - $\mathrm{CO}_{2}, \mathrm{O}_{2}, \mathrm{~N}_{2}$}

The permeances of the plasticized cellulose acetate membranes and the polyimide membranes as measured by the multicomponent system are shown in Figures 12 and 13. The permeance of $\mathrm{CO}_{2}$ in either membrane is similar to that obtained in the single component system. The permeance of $\mathrm{CO}_{2}$ is on the average $75 \%$ higher 


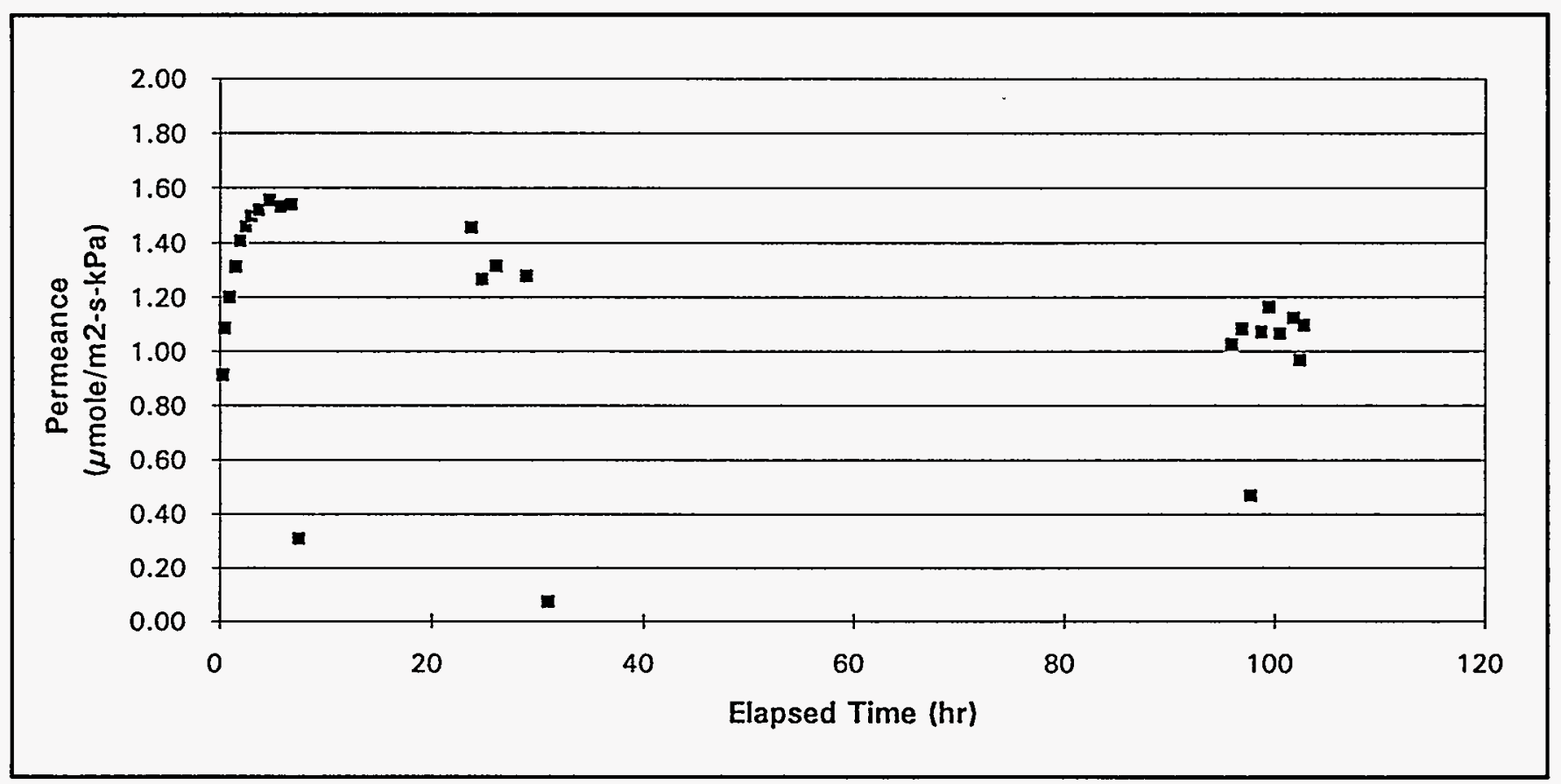

FIGURE 11. CA Plasticization @200 psi

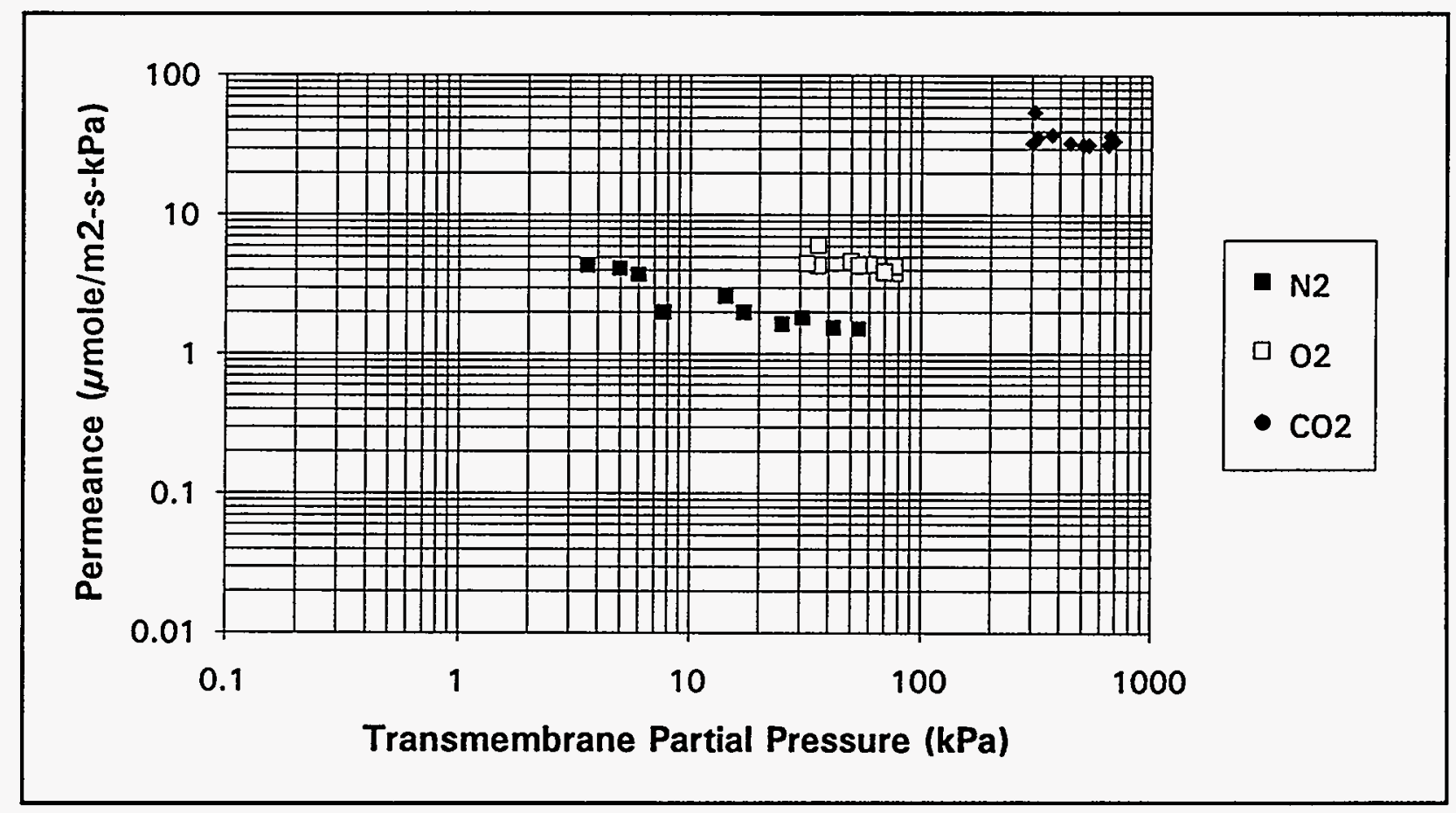

FIGURE 12. CA Membrane/Three Components 


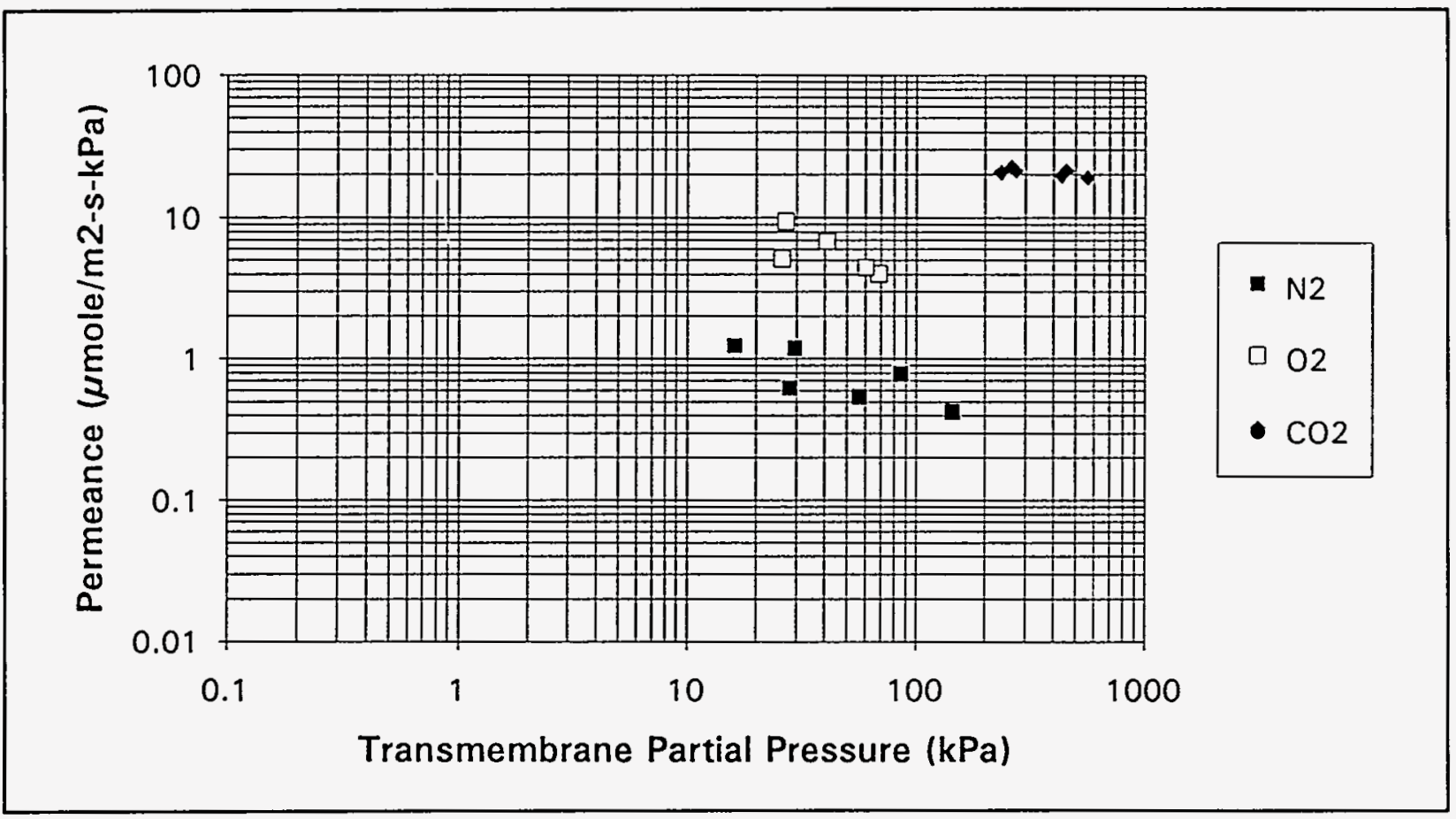

FIGURE 13. PI Membrane/Three Components

for the cellulose acetate membrane than the polyimide membrane. On the other hand, the $\mathrm{N}_{2}$ permeance shows a significant increase for the plasticized over unplasticized cellulose acetate membrane. In contrast, $\mathrm{N}_{2}$ permeance through the polyimide membrane in the flow system showed only a moderate increase over the single component system indicating that it was not plasticized by $\mathrm{CO}_{2} . \mathrm{N}_{2}$ permeance through the polyimide membrane was about three times that through the cellulose acetate membrane. Therefore, under more realistic operating condi-tions, the polyimide membrane had a better $\mathrm{CO}_{2} / \mathrm{N}_{2}$ separation factor than the cellulose acetate membrane (26 vs. 14), and will better separate the two components. Unfortunately, the $\mathrm{CO}_{2} / \mathrm{O}_{2}$ separation factor is slightly lower with the polyimide membrane than with the cellulose acetate membrane ( 8 and 3 , respectively). A lower $\mathrm{CO}_{2} / \mathrm{O}_{2}$ separation factor will allow more $\mathrm{O}_{2}$ to penetrate the membrane and exit the system, resulting in an operating cost trade-off for the use of the polyimide membrane versus the cellulose acetate membrane. Both membranes are selective for $\mathrm{CO}_{2}$ over $\mathrm{N}_{2}$, and either could be expected to perform the separation desired, but the data indicates that the polyimide membrane is more suitable for our purposes than the cellulose acetate membrane.

Multicomponent Studies - $\mathrm{CO}_{2}, \mathrm{O}_{2}, \mathrm{~N}_{2}, \mathrm{nC}_{1}-\mathrm{C}_{3}$

Figure 14 shows the permeances of $\mathrm{N}_{2}, \mathrm{O}_{2}, \mathrm{CO}_{2}$, and the light hydrocarbons calculated from the multicomponent system studies for the cellulose acetate membrane. Note that a log scale is used on the ordinate axis; therefore, permeance differences that appear small may actually be quite large. The permeance of $\mathrm{CO}_{2}$ through cellulose acetate is shown to be about an order of magnitude higher than the permeances of the hydrocarbons. Methane is slightly more permeable than ethane or propane, showing a trend of decreasing permeance with increasing molecular weight; however, the trend is not very strong in this case.

Figure 15 shows the same plot as Figure 14 but for the polyimide membrane. In Figure 15, an 


\section{RFP-4641}
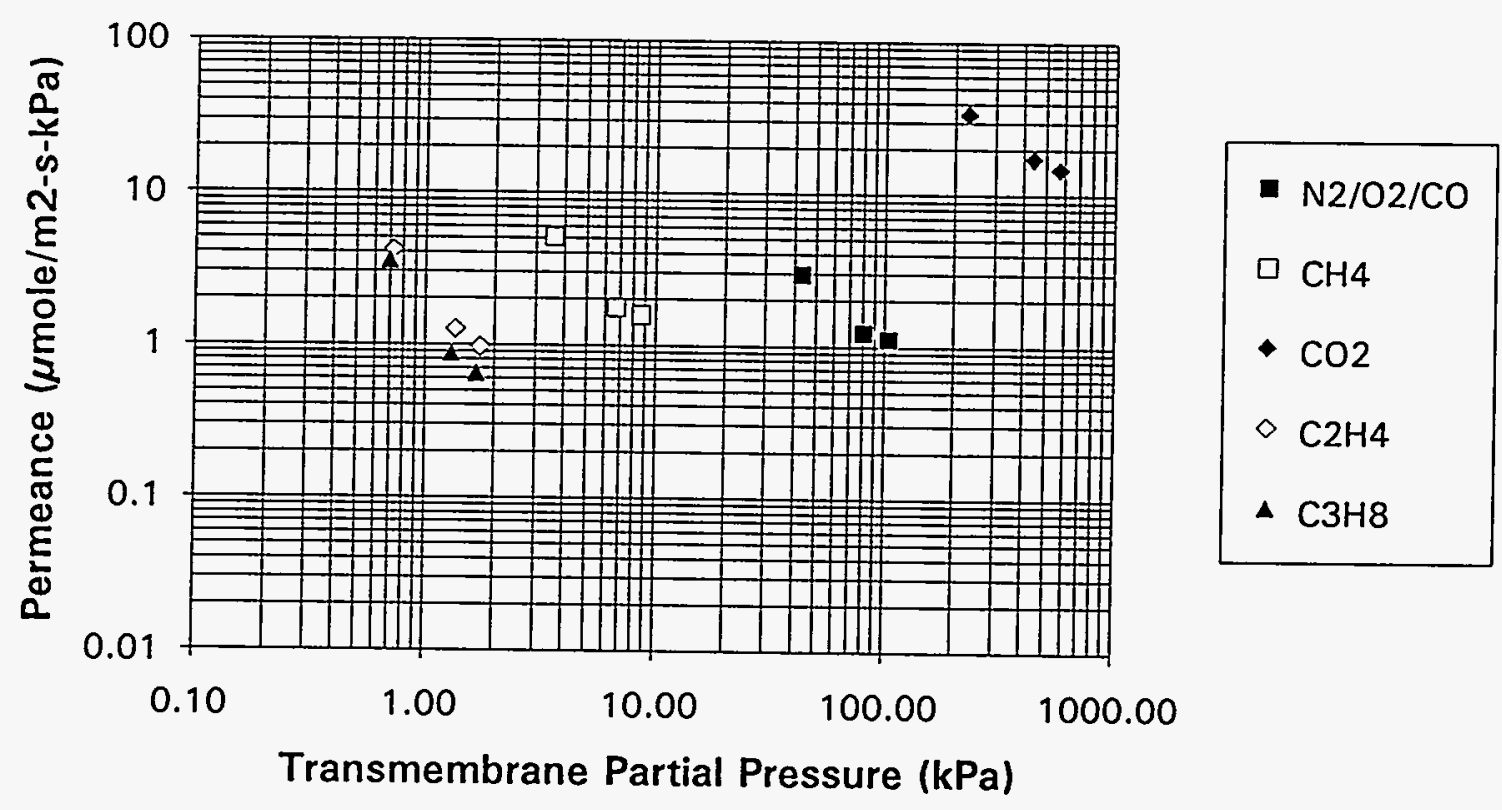

FIGURE 14. CA Membrane/Seven Components

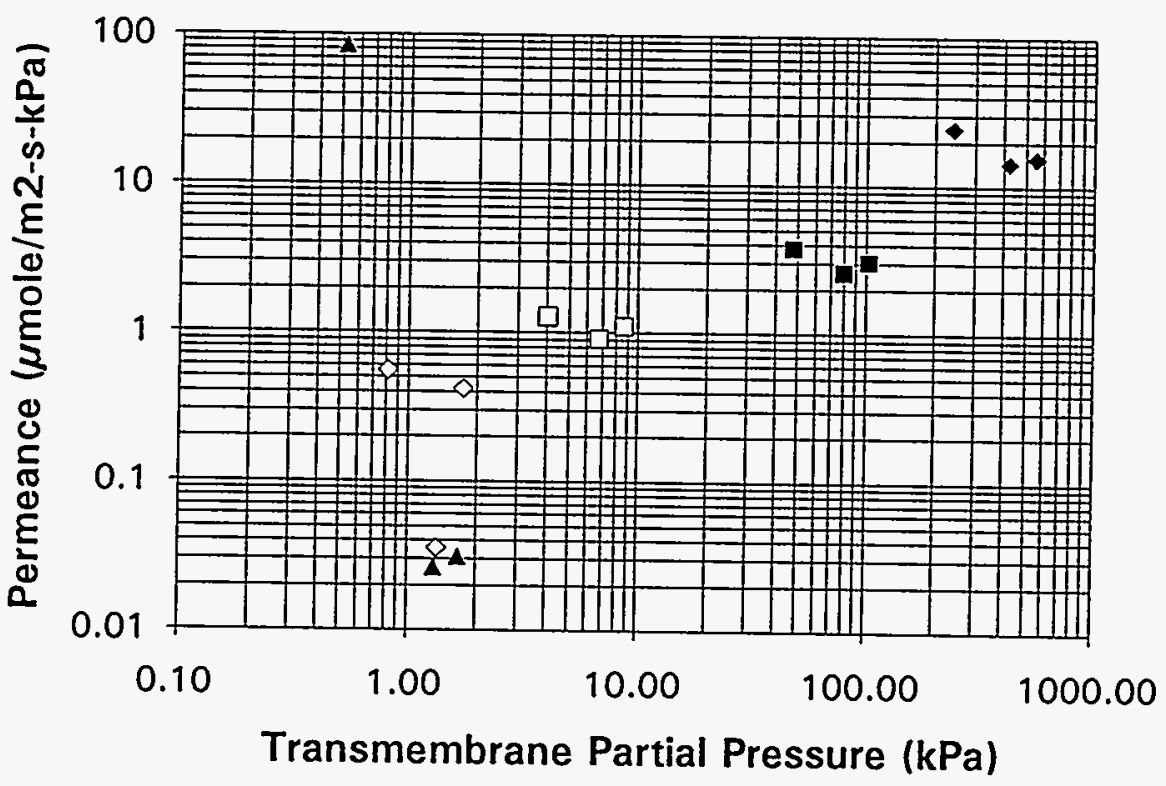

- $\mathrm{N} 2 / 02 / \mathrm{CO}$

$\square \mathrm{CH} 4$

- $\mathrm{CO} 2$

$\diamond \mathrm{C} 2 \mathrm{H} 4$

$\triangle \mathrm{C} 3 \mathrm{H} 8$

FIGURE 15. PI Membrane/Seven Components 


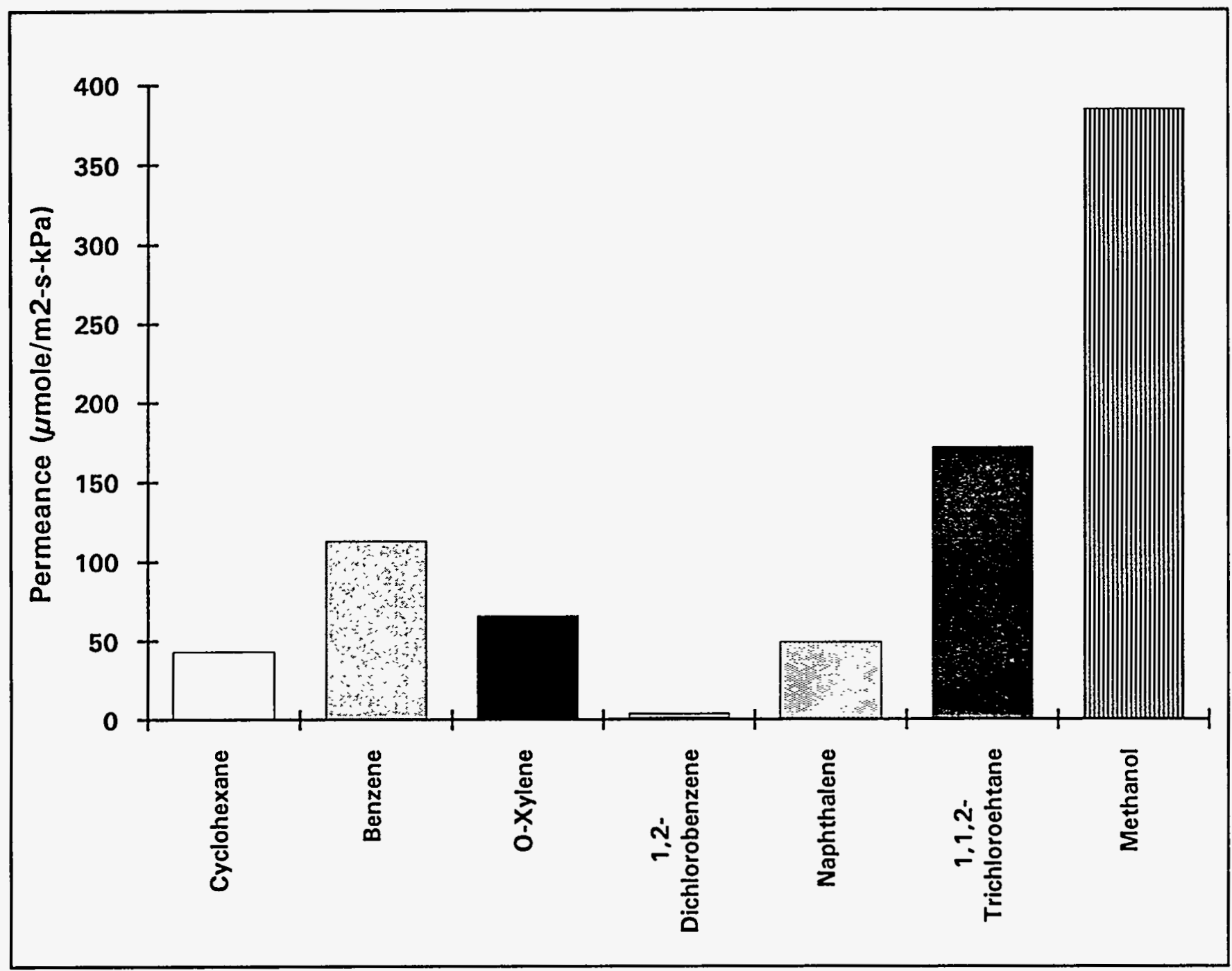

FIGURE 16. Organic Vapor Permeance

exceptionally high value for propane permeance through the polyimide membrane can be seen. This high value is thought to be a result of experimental error. Other permeances for propane were found to be about four orders of magnitude lower. $\mathrm{CO}_{2}$ permeance is seen to be slightly more than an order of magnitude greater than the permeance of methane. The permeances of hydrocarbons through the polyimide membrane decreases greatly, with increasing molecular weight dropping nearly two orders of magnitude from methane to propane. This relationship between molecular weight and permeance is expected because larger molecules should be more hindered as they try to diffuse across the solid membrane. On the basis of these results, the polyimide membrane is expected to be superior to the cellulose acetate membrane with regard to separation of $\mathrm{CO}_{2}$ and light hydrocarbons.

\section{Liquid Organic Permeation Study}

The results of the upright cup organic vapor permeation studies for the cellulose acetate membrane are shown in Figure 16. In general, 


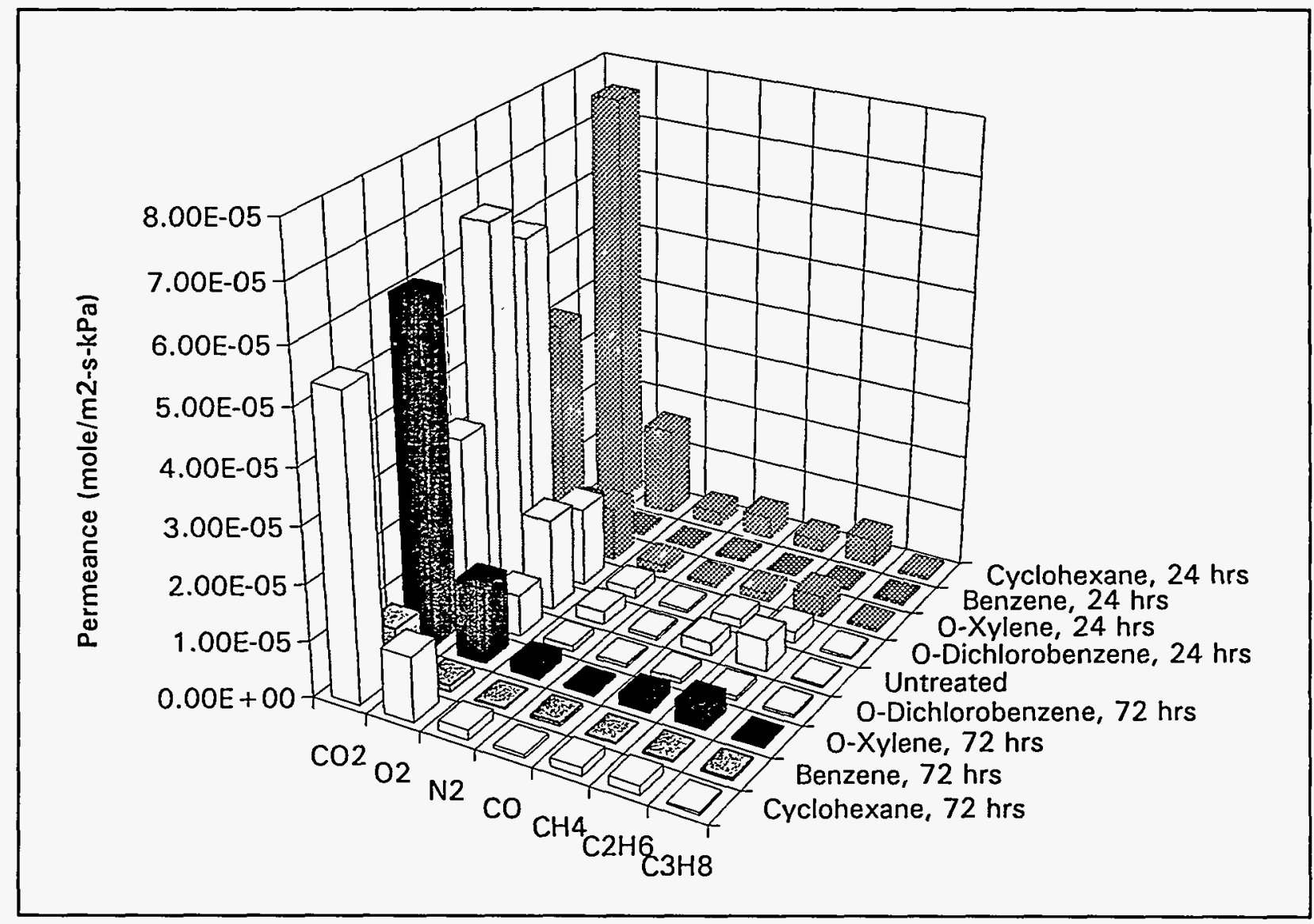

FIGURE 17. Polyimide @ 50 psig

small polar molecules, such as methanol, tended to permeate the cellulose acetate membrane rapidly, as did aromatics. The high permeance of the small polar molecules could be expected because in size and polarity they are similar to $\mathrm{CO}_{2}$. The cellulose acetate membrane is thought to contain what might be described as "channels" through which the aromatics can easily flow. Increasing the size of the groups attached to the benzene ring tends to hinder this movement and reduce its permeance. A decrease in permeance can be seen going from benzene to 0 -xylene to naphthalene to 1,2-dichlorobenzene. This sequence effectively changes the substituted groups from hydrogen to methane to benzene to chlorine. Much larger molecules like dioxin would probably permeate even more slowly because of greatly increased steric hinderance.

\section{Membrane Degradation Study}

When exposed to 1,2-dichlorobenzene for 24 hours, the polyimide membrane showed no evidence of degradation. (See Figures 17 and 18.) When the exposure time was increased to 72 hours, a decrease in permeance of approximately $50 \%$ was observed for all gases. This decrease indicates a slow diffusion of the 1,2-dichlorobenzene into the membrane material, resulting in degradation at 72 hours that did not occur within 24 hours. Even after the degradation from a 72 hour exposure, the separation achieved is satisfactory because of an equal or greater reduction also seen with the other gases. Exposure of the polyimide membrane to either cyclohexane or 0 -xylene resulted in no significant degradation of the performance of the membrane. However, 


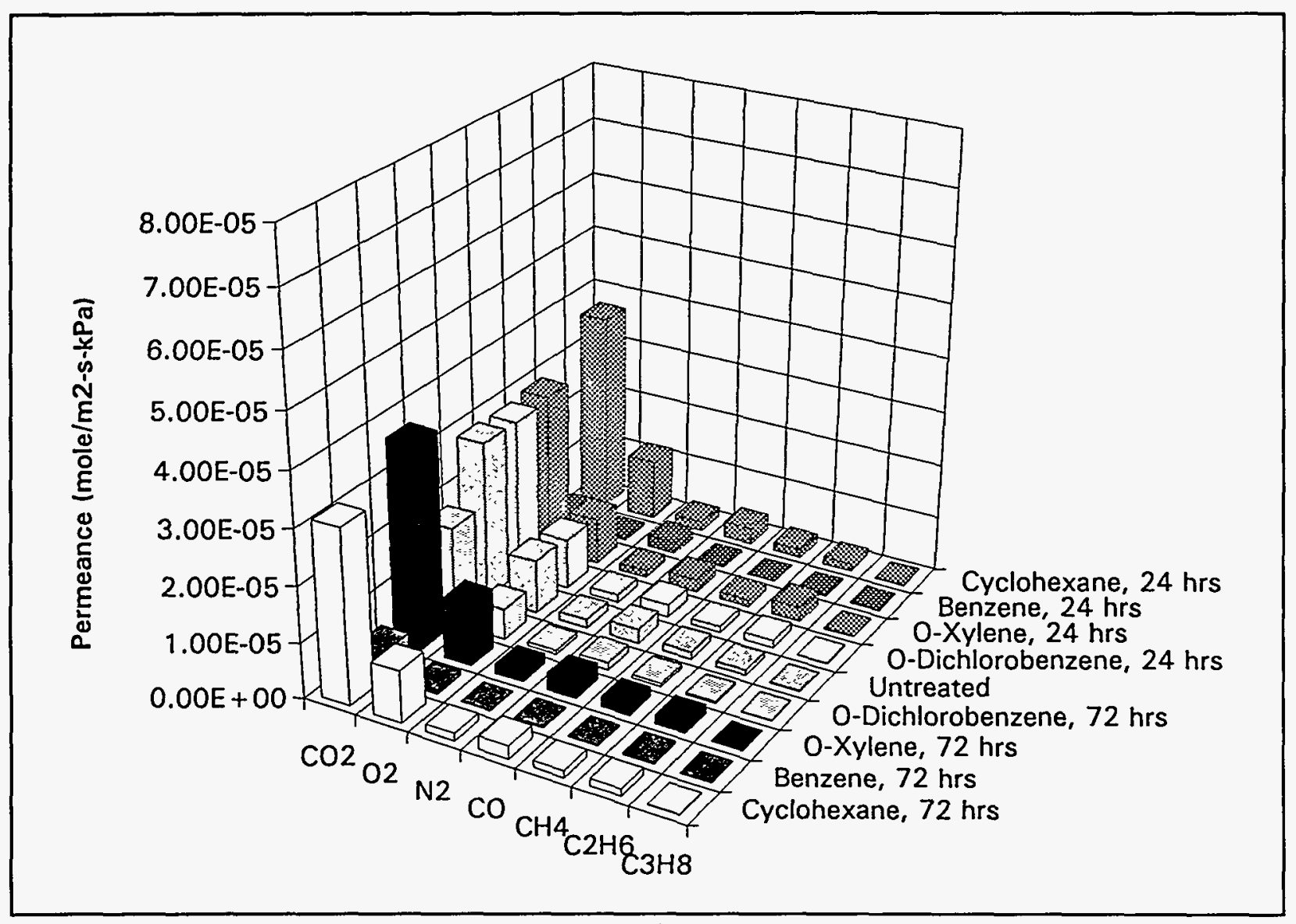

FIGURE 18. Polyimide @ 200 psig

when exposed to benzene, the polyimide membrane demonstrated severe deterioration in its performance under all test conditions. Attempts to regenerate the module through removal of the benzene under vacuum were unsuccessful. A cursory examination of the hollow fibers revealed severe and irreversible degradation.

The cellulose acetate membrane, in general, showed significant degradation resulting from exposure to all the aromatic compounds. (See Figures 19 and 20.) This degradation is based on the increase in the permeance of ethane following exposure coupled with the decrease in $\mathrm{CO}_{2}$ permeance. Inspection of the membrane after exposure to benzene showed severe irreversible damage to the membrane. Cyclohexane had little effect on the membrane.
In summary, the resistance to degradation of the polyimide membrane was good when exposed to cyclohexane, o-xylene, and 1,2-dichlorobenzene but very poor when exposed to benzene. The degradation resistance of the cellulose acetate membrane upon exposure to solvents is considered poor for the aromatic solvents and good for cyclohexane; however, a point to note is that during conditioning, the membrane was exposed to concentrations of organics far beyond those expected during operation in an off-gas treatment system. While use of either membrane would provide significant protection against environmental releases during upset conditions and during extended operation, prudence would dictate that where exposure to benzene is possible, the membrane should be inspected frequently. 


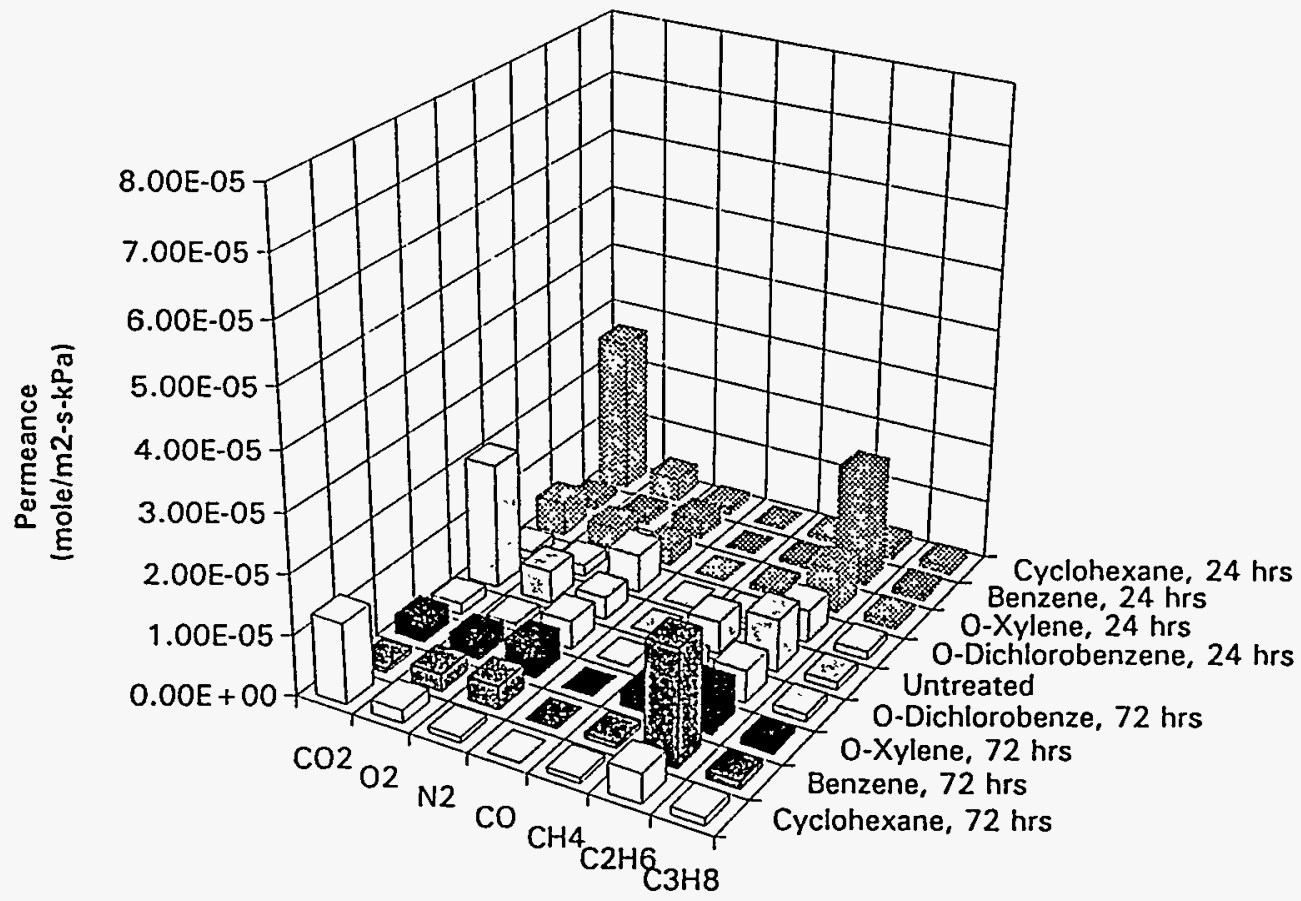

FIGURE 19. Cellulose Acetate @ 50 psig

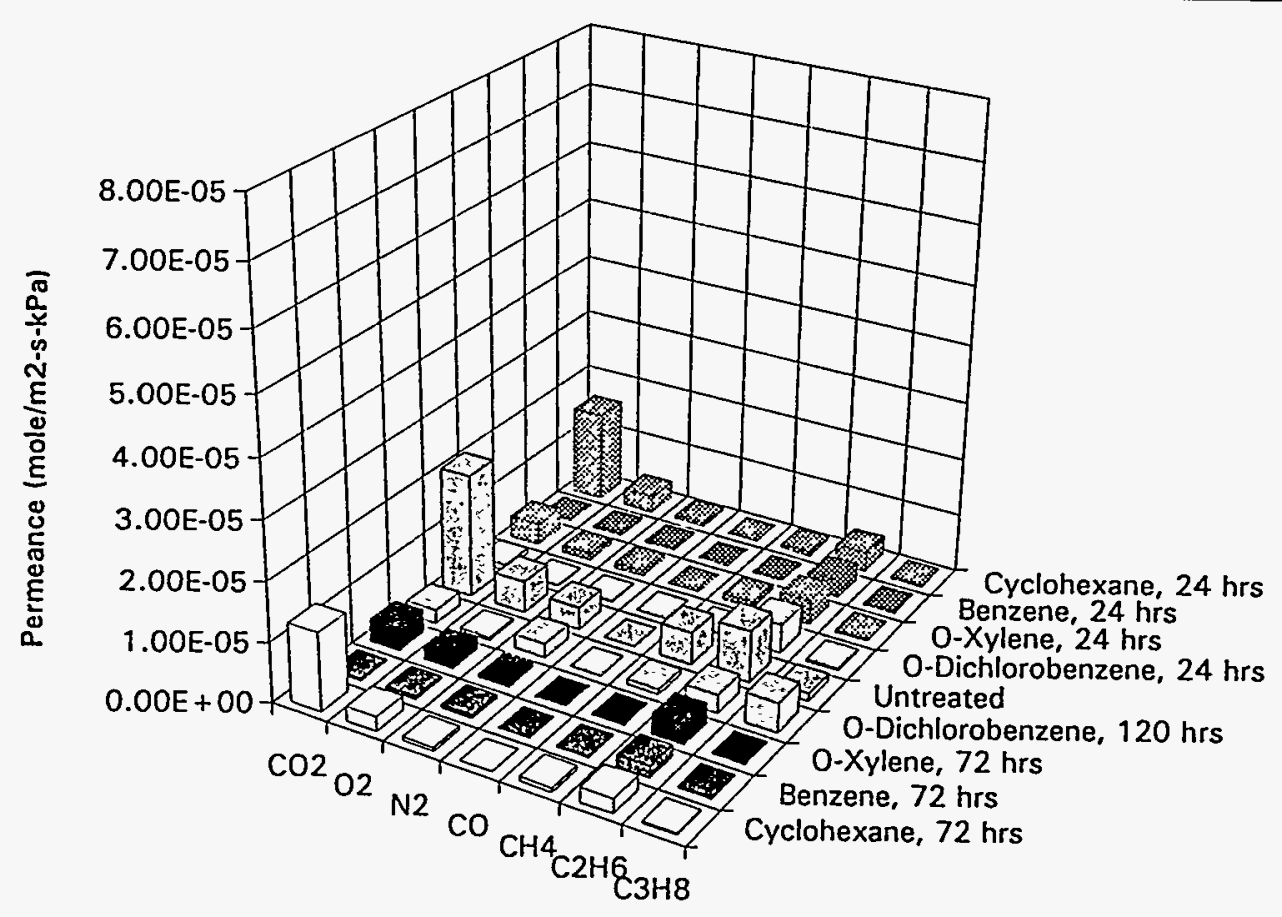

FIGURE 20. Cellulose Acetate @ 200 psig 


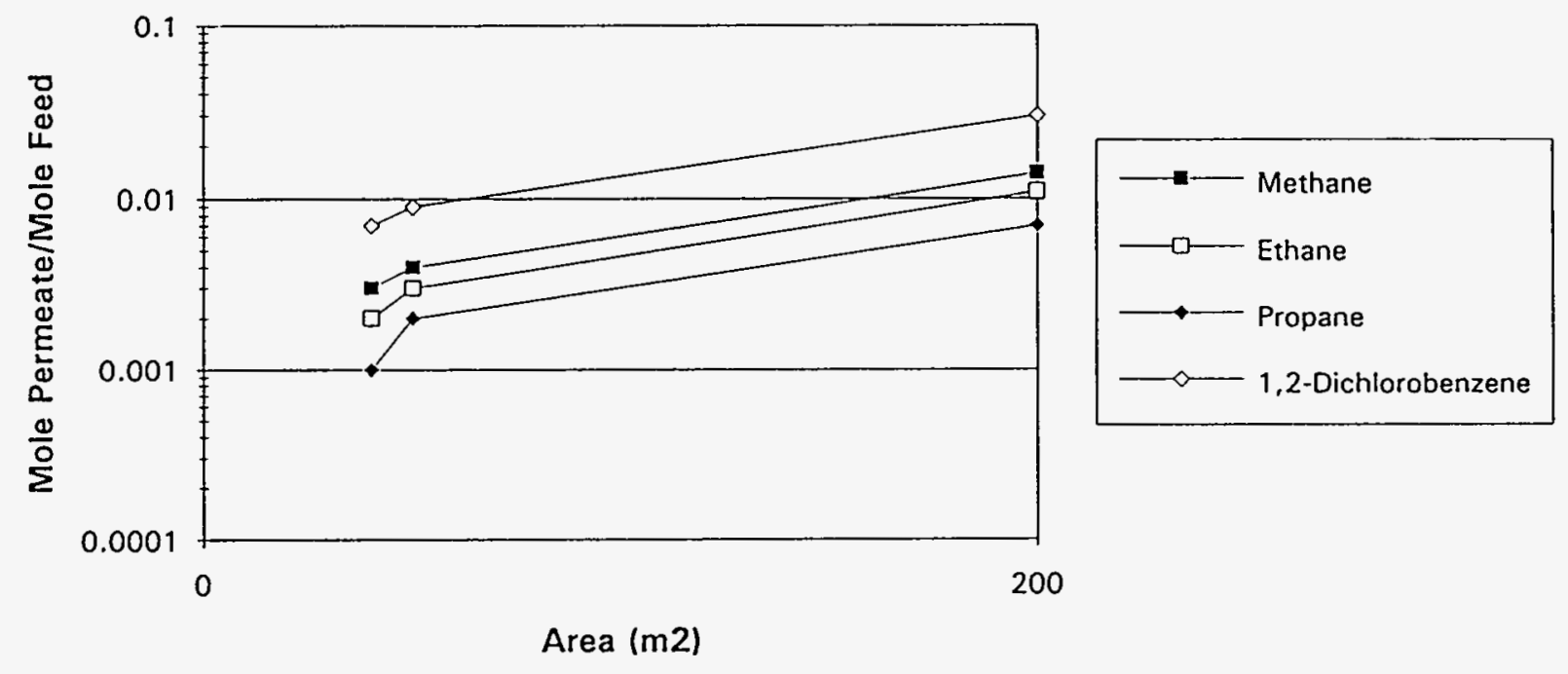

FIGURE 21. CA Membrane Simulation - Effect of Membrane Area

\section{Simulation Results}

Using the results of the experimental work, a proprietary seven component simulation program was run at NIST to estimate the emission reduction possible with membrane technology. In Case 1 , permeances similar to those determined for the cellulose acetate membrane were used for the simulation. In Case 2, lower permeances for the $\mathrm{C}_{1}-\mathrm{C}_{3}$ compounds, similar to those empirically determined for the polyimide membrane, were used for the organic compounds. The permeance of 1,2-dichlorobenzene through the polyimide membrane could not be determined by methods designed for this study. These results are shown in Figures 21-24. Plotted on the vertical axis is the ratio of the organic concentration in the permeate to the organic concentration in the feed. This emissions ratio is effectively one minus the emission reduction that is predicted by the simulation model. Figure 21 shows the predicted emissions ratio plotted as a function of membrane area for Case 1 values. The same is plotted in Figure 22 for Case 2 values. These values show that emissions for each organic component should be reduced by at least $97 \%$ for Case 1 and $99 \%$ for Case 2. Figure 23 shows the emission ratio plotted as a function of feed pressure for Case 1 values and the same for Case 2 values in Figure 24. Here the emissions of each organic component are reduced by at least $93 \%$ for Case 1 and again by $99 \%$ for Case 2 .

\section{CONCLUSIONS}

Several conclusions can be made based on these results.

First, the feasibility of using gas separation membranes for pollution control has been demonstrated. The measured $\mathrm{CO}_{2}, \mathrm{O}_{2}$, and $\mathrm{N}_{2}$ permeabilities are sufficient to allow the use of membrane technology for off-gas emissions control. The membrane module is small $(10-20$ cubic feet) relative to most membrane processes and small relative to the size of the other FBU process equipment. Where completeness of data allows comparison, the results indicate that polyimide is the preferred material for this application.

Second, the degradation studies indicate that exposure to high concentrations of benzene could be a problem for the polyimide membrane. Exposure 


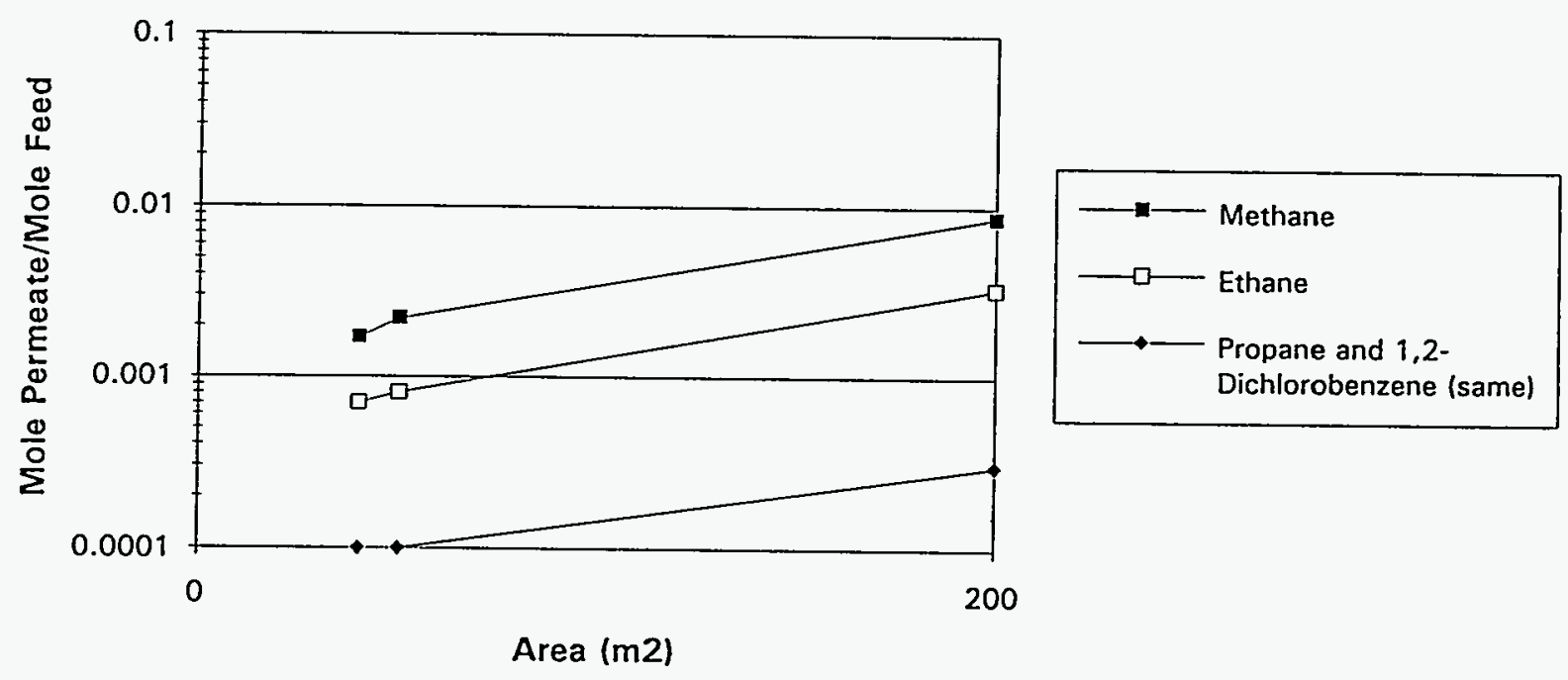

FIGURE 22. PI Membrane Simulation - Effect of Membrane Area

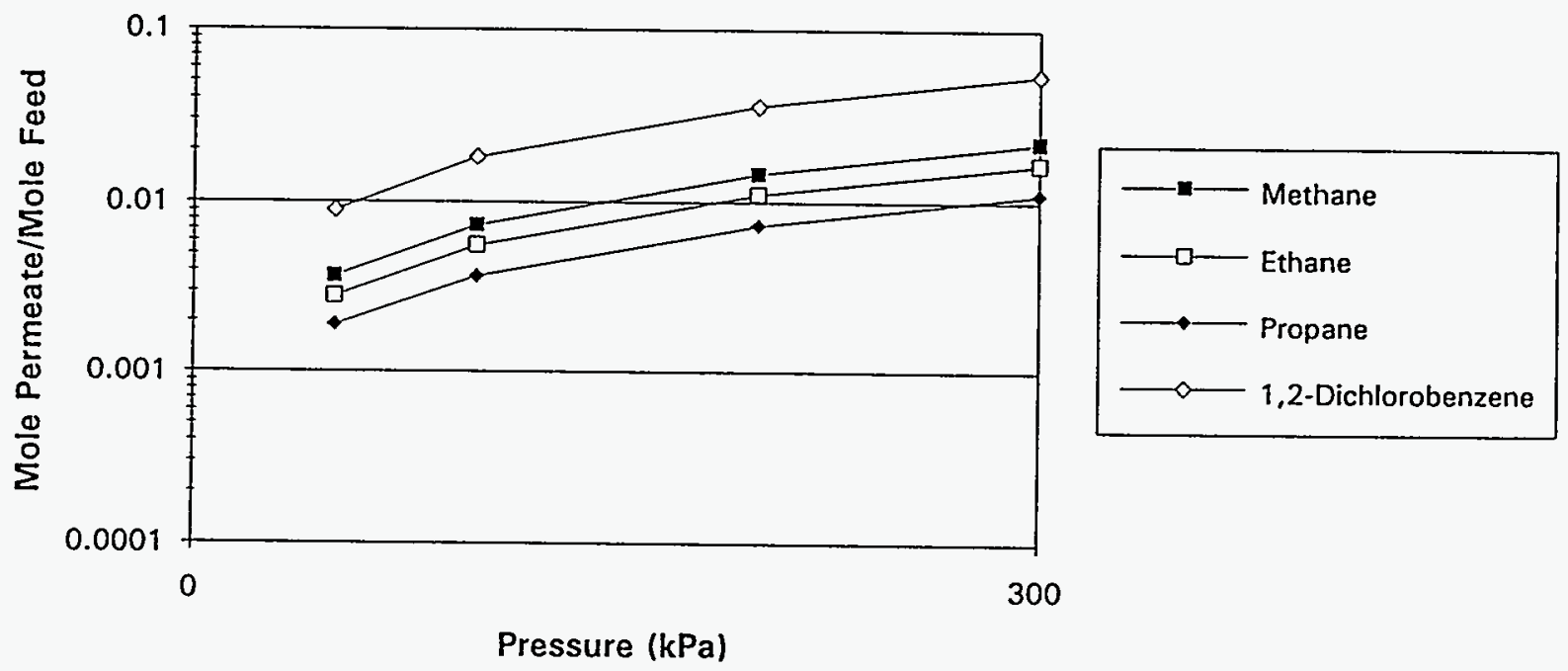

FIGURE 23. CA Membrane Simulation - Effect of Pressure

to high concentrations of aromatic compounds in general could be a problem for cellulose acetate membranes. This problem is not expected to exist during actual operation of an off-gas treatment system because the membranes would be exposed to these compounds in concentrations of less than one part per million (ppm).

Third, membrane module simulations predict emissions reductions for each model compound 


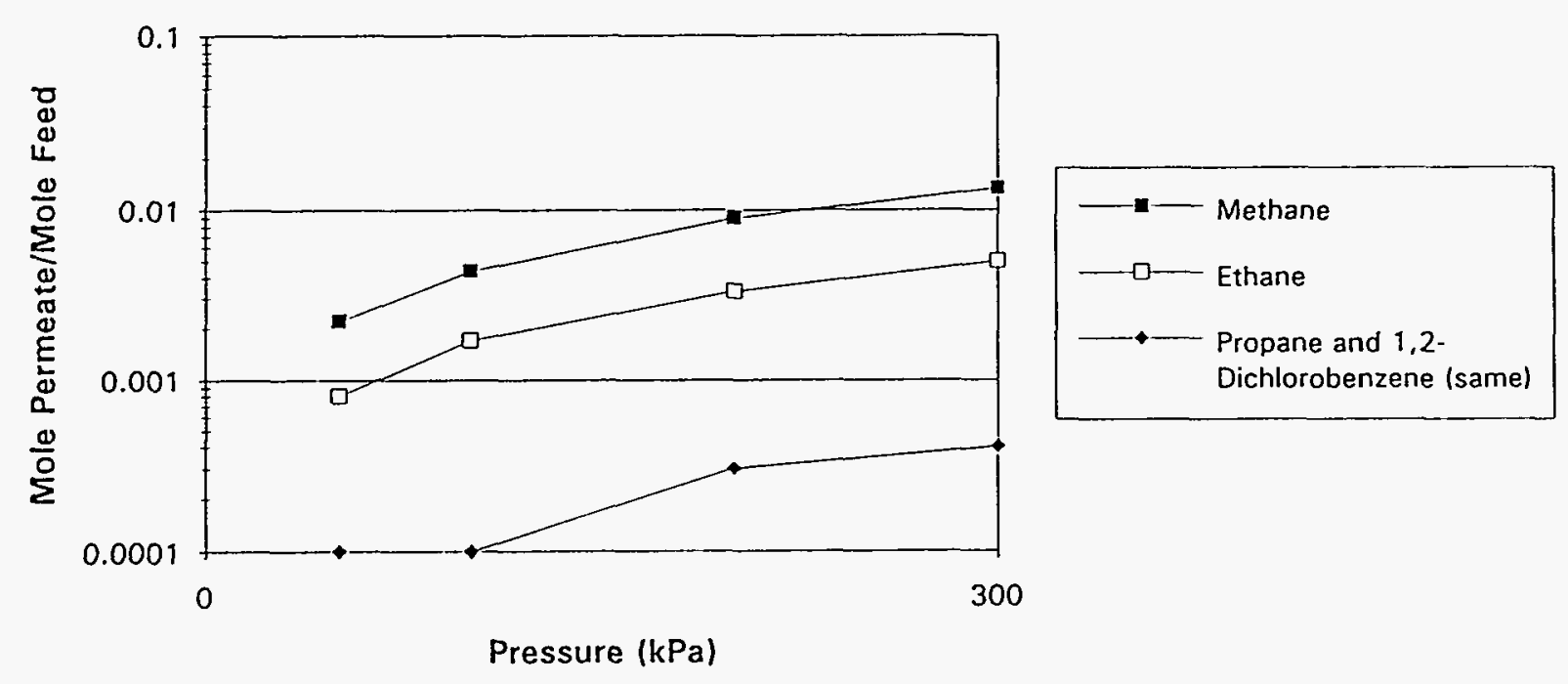

FIGURE 24. PI Membrane Simulation - Effect of Pressure

of $97 \%$ for the worst-case membrane tested, and exceeding $99 \%$ for an optimum membrane material. Emissions of specific organic compounds could be reduced by as much as four orders of magnitude.

\section{RECOMMENDATIONS}

Based on this preliminary study, the following recommendations are made:

1. Additional membranes should be tested for applicability to off-gas treatment to ensure that the best candidate membranes are identified for further testing.

2. The permeances of vapors of higher molecular weight organic liquids (such as dioxins and furans) should be determined in the multicomponent flow module. The three best candidate membranes determined from recommendation 1 should be tested for their permeabilities to these compounds to provide more accurate prediction of the performance of the membrane systems for pollution control.
3. Additional work should be performed to determine the degradation of candidate membranes resulting from exposure to organic compounds, providing more conclusive information on the sensitivity of the membranes to degradation by compounds at concentrations nearer those expected during operation.

4. Long term durability tests of the membranes should be conducted at pilot scale for a final demonstration of the applicability of the technology to pollution control.

\section{REFERENCES}

1. D. M. Stull and J. O. Golden, RFP-4485 Liquefaction and Storage of Thermal Treatment Off-Gases, EG\&G Rocky Flats, Rocky Flats Plant, Golden, CO, September 8, 1992.

2. M. S. Dinello, R. S. Narayan, and C. J. Patton, "Bulk $\mathrm{CO}_{2}$ Removal Achieved Through Membrane Separation," SPE Production Engineering, 4(1), pp 88-92, 1989. 


\section{BIBLIOGRAPHY}

R. T. Chern, W. J. Koros, H. B. Hopfenberg, and V. T. Stannett, "Material Selection for Membrane-Based Gas Separations," Materials Science of Synthetic Membranes, edited by D. R. Lloyd, American Chemical Society, Washington, D. C., pp 25-46, 1985.

A. B. Coady and J. A. Davis, " $\mathrm{CO}_{2}$ Recovery by Gas Permeation," Chemical Engineering Progress, 78(10), pp 44-49, 1982.

M. S. Dinello, R. S. Narayan, and C. J. Patton, "Bulk $\mathrm{CO}_{2}$ Removal Achieved Through Membrane Separation," SPE Production Engineering, 4(1), pp 88-92, 1989.

S. M. Jordan, W. J. Koros, and G. K. Fleming, "The Effects of $\mathrm{CO}_{2}$ Exposure on Pure and Mixed Gas Permeation Behavior: Comparison of Glassy Polycarbonate and Silicone Rubber," Journal of Membrane Science, 30, pp 191-212, 1987.

W. J. Koros and M. W. Hellums, "Gas Separation Membrane Material Selection Criteria: Differences for Weakly and Strongly Interacting Components," Fluid Phase Equilibria, 53, pp 339-354, 1989.

W. J. Koros and R. T. Chern, "Separation of Gaseous Mixtures Using Polymer Membranes," Handbook of Separation Process Technology, edited by R. W. Rousseau, John Wiley \& Sons, New York, N. Y., 1987.

W. H. Mazur and M. C. Chan, "Membranes for Natural Gas Sweetening and $\mathrm{CO}_{2}$ Enrichment, Chemical Engineering Progress, 78(10), pp 38-43, 1982.

W. J. Schell and C. D. Houston, "Spiral Wound Permeators for Purification and Recovery," Chemical Engineering Progress, 78(10), pp 33-37, 1982.

R. W. Spillman, "Economics of Gas Separation Membranes," Chemical Engineering Progress, 85(1), pp 41-62, 1989.

D. M. Stull and J. O Golden, RFP-4485 Liquefaction and Storage of Thermal Treatment Off-Gases, EG\&G Rocky Flats, Rocky Flats Plant, Golden, CO, September 8, 1992.

P. C. Wankat, Rate Controlled Separations, Elsevier Science Publishing Co., New York, N. Y., 1990.

R. R. Zolandz and G. K. Fleming, "Part II, Gas Permeation," Membrane Handbook, edited by W. S. W. Ho and K. K. Sirkar, Van Nostrand Reinhold, New York, N. Y., pp 17-101, 1992. 


\section{APPENDIX A}

Peer Review Panel Summary Report for Technical Determination of Mixed Waste Incineration Off-Gas Systems for Rocky Flats*

\section{INTRODUCTION}

A Peer Review Panel was convened on September 15-17, 1992, in Boulder, Colorado. The members of this panel included representatives from the Department of Energy (DOE), the Environmental Protection Agency (EPA), and DOE contractors, along with invited experts in the fields of air pollution control and waste incineration. A complete list of the panel members is provided at the end of Appendix A.

The primary purpose of this review panel was to make a technical determination if a hold, test, and release off-gas capture system should be implemented in the proposed Rocky Flats Plant (RFP) mixed incineration system or if a state-of-the-art continuous air pollution control and monitoring system should be utilized as the sole off-gas system.

All of the evaluations by the panel were based upon the use of the fluidized bed unit proposed by Rocky Flats. The continuous air pollution control and monitoring system option evaluated was developed specifically for the Fluidized Bed Unit (FBU) and cannot be generalized to apply to other systems.

\section{APPROACH}

The approach used by the panel involved the following:

Presentations on History and Background of RF FBU

Paul Williams

EG\&G Rocky Flats, Inc.

Identification of Criteria for Assessment of Alternative Off-Gas Capture Systems

Separate presentations on Alternative Off-Gas Capture Systems:

$$
\begin{aligned}
& \mathrm{CO}_{2} \text { Off-Gas Capture } \\
& \text { Dennis Stull } \\
& \text { EG\&G Rocky Flats, Inc. }
\end{aligned}
$$

Carbon Absorption Hold, Test, and Release

Robert Ryan

Los Alamos Technical Office-RF

Analysis of Chemical Technologies for $\mathrm{CO}_{2}$ Off-Gas Containment

Tim Burns

Los Alamos Technical Office-RF

\footnotetext{
* Although this report has been slightly edited, the original content remains exactly the same.
} 
Discussions on each option:

Presentation on status of actinide volatilization studies

O. Krikorian

Lawrence Livermore National Laboratory

Presentation on the results of the study on the state-of-the-art assessment of continuous flow APC systems and monitoring systems for Rocky Flats

Randy Seeker

EER Corporation

Comparison of advantages of options of (1) continuous air pollution control and monitoring system vs (2) continuous air pollution control and monitoring system + off-gas capture

Critical flaw assessment of continuous air pollution control and monitoring system

Critical flaw assessment of continuous air pollution control and monitoring system + off-gas capture

Fluidized bed assessment

A list of materials reviewed by the peer review panel in conducting this review is provided at the end of Appendix A.

\section{RESULTS}

The panel first defined advantages for the two options: Option 1, continuous air pollution control and monitoring; and Option 2, continuous air pollution control and monitoring plus hold, test, and release of off-gas capture system. The summary of these advantages is as follows:

\section{Option 1 Advantages}

$\begin{array}{ll}\text { - } & \text { Proven technology } \\ \text { - } & \text { Limplicity } \\ \text { - } & \text { Caps complexity } \\ \text { - } & \text { Less costly } \\ \text { - } & \text { Ability to continuously measure radionuclids at background levels in stack } \\ \text { - } & \text { Operability } \\ \text { - } & \text { Reliability } \\ \text { - } & \text { Maintainability }\end{array}$




\section{Option 2 Advantages}

- Increased time to sample and analyze

- Public perception of increased safety and control

\section{CRITICAL FLAW ASSESSMENT}

The next step for the Peer Review Panel was to conduct a critical flaw analysis for each of the two options. The panel's conclusions were as follows:

\section{Critical Flaw Assessment of Continuous Air Pollution Control and Monitoring (Option 1)}

No critical flaws were identified. A lack of detailed information about system performance exists.

\section{Critical Flaw Assessment of Continuous Air Pollution Control and Monitoring Plus Hold, Test, and Release Off-Gas Capture System (Option 2)}

The components of the off-gas capture system have been developed and used by industry for purposes other than mixed waste incineration of off-gas capture. Only conceptual studies on the use of these technologies for mixed waste incinerator effluent have been conducted to date. The basis of this evaluation of critical flaws was those conceptual studies.

The critical flaws identified in this review were as follows:

- The system is not needed over the Continuous Air Pollution Control and Monitoring. The current state-of-the-art continuous air pollution control system has the potential to meet and exceed all of the current and anticipated regulations applicable to Rocky Flats.

- The proposed hold, test, and release off-gas capture system cannot handle noncondensible gases such as nitrogen and $\mathrm{NO}_{\mathrm{x}}$. Particularly critical to systems with in-leakage of air is the separation of these gases so that they will not build up in the flue gases and therefore need to be vented. Some additional technologies other than those proposed will be required for separation of these gases.

- The increased complexity of Option 2 offsets any perceived advantages over the Continuous Air Pollution Control and Monitoring option. The number of additional components that must be added in Option 2 will likely decrease reliability of the overall integrated system. In addition, Option 2 is harder to control. For example, Option 2 requires a closed system which recycles certain percentages of gases back to the combustion zone. These return gases could have variable amounts of oxygen that increase the complexity of oxygen control in the thermal treatment unit.

- Representative samples are difficult to obtain from the captured off-gases because of uncertain disposition of particulate matter and radionuclides.

- No regulatory framework is in place for handling the release of off-gases, since they would be considered hazardous waste under the "derived-from-rule." 


\section{RFP-4641}

\section{CONCLUSIONS}

The panel determined that no need is present for the addition of an off-gas capture test and release system to continuous air pollution control for RFP mixed waste incineration. The continuous APC/Monitoring system has substantial advantages over Option 2 . The OC option adds unnecessary complexity and burdens the system with unproven for this application. The reasons to even consider the off-gas capture test and release system are to provide longer times for sampling and analysis and increased public perception of safety. In reality, no increase in safety results. The panel is of the opinion that risks will not be reduced with the addition of the OC. The panel also challenged the ability to take representative samples from the captured effluent.

No further development of the OC systems is recommended. The panel did not rant the three proposed options for $\mathrm{OC}$ in light of this conclusion.

\section{RECOMMENDATIONS}

The panel made the following recommendations:

1. Conduct a comprehensive risk assessment that includes an assessment of conservative, realistic, and worst case emissions in order to assess performance standards for the incineration system.

2. Since no critical flaws were identified for the CAPC/M, the panel recommends that the implementation proceed on a logical develop-ment path to generate information about the overall system performance. The development for Rocky Flats should conclude:

- Parametric testing, including upset conditions

- Integration of components (systemization)

- Performance of real-time continuous radionuclide monitoring

- Use of engineering analysis procedures on the fate of radioactive and hazardous metals in Rocky Flats mixed waste incineration systems.

The panel suggested that Mixed Waste Integrated Program (MWIP) should support the RFP in the following ways:

- Address total systems issues relative to the optimization of mixed waste incineration

- Support studies on the fate of metals in mixed waste incineration for the practical interpretation and generalization of the results

- Develop real time radionuclide monitoring techniques

- Develop real time metal monitoring techniques

3. The panel was not charged with the evaluation of the fluidized bed unit (FBU) versus other types of incinerators for treatment of mixed waste at Rocky Flats. A cursory evaluation did not uncover any critical flaws with the FBU; however, additional in-depth, technical review is recommended to ensure that optimum choice of incinerator is made.

4. The results of this technical assessment should be professionally communicated to the general public. This communication could include the use of non-technical language, the development of a public relations program. and the use of an independent technical peer review. 
PEER REVIEW PANEL MEMBERS AND PARTICIPANTS

Nina Bergan French

Sandia National Laboratories

Livermore, CA

Robert H. Karlsson

SAIC/EM-323

Washington, DC

Ralph A Koenig

Merlin Corporation

Boulder, $\mathrm{CO}$

C.C. Lee, Ph.D.

U.S. EPA

Cincinnati, $\mathrm{OH}$

Edward J Martin

HMCRI

Greenbelt, MD

David C. Moody

Los Alamos Technical Office-RF

Golden, CO

Robert R. Ryan

Los Alamos Technical Office-RF

Golden, CO

William Randall Seeker

EER

Irvine, CA

Greg Sprenger

EG\&G Rocky Flats, Inc.

Golden, CO
Dennis M. Stull

EG\&G Rocky Flats, Inc.

Golden, CO

Reginald W. Tyler

Department of Energy

Rocky Flats, Inc.

Paul Williams

EG\&G Rocky Flats, Inc.

Golden, CO

\section{$\underline{\text { Facilitator }}$}

Karen Rhine Itomura

Activate, Inc.

Benton, IL

\section{Observers and Presenters}

Tim Burns

Los Alamos Technical Office-RF

Golden, CO

John O. Golden

Colorado School of Mines

Golden, CO

Oscar H. Krikorian

Lawrence Livermore National Laboratory

Livermore, CA

Boyce W. Logsdon

EG\&G Rocky Flats, Inc.

Golden, CO 


\section{REFERENCE LIST FOR THE TECHNICAL PEER REVIEW}

Los Alamos National Laboratory MEE-4-91-379 9/26/91

RFP Incinerator Off-Gas Handling and Storage Concept Evaluation
Authors:
M.W. Burkett
W.J. Parkinson
D.C. Nelson
A.L. Bowman

Los Alamos National Laboratory LA-UR-91-3206 10/03/91

Activated Carbon Adsorption Storage of Incinerator Off-Gases an

Rocky Flats: Preliminary Design

Author: C.O. Grigsby, Ph.D.

Lawrence Livermore National Laboratory Draft 01/10/92

An Investigation of the Need for the Hold, Test, and Release (HT\&R)

Option for Rocky Flats
Authors:
R.S. Upadhye
M.G. Adamson
J.F. Cooper
A.K. Lee

Los Alamos National Laboratory LA-UR-91-3326 09/30/91

Author: N.N. Sauer

EG\&G Rocky Flats, Inc. Draft 03/20/92

Liquefaction and Storage of Thermal Treatment Off-Gases
Authors:
D.M. Stull
J.O. Golden, Ph.D.

Energy and Environmental Research Corporation EPA Contract 68-CO-0094 Draft 05/20/92

State-of-the-Art Assessment of APC Systems and Monitoring

Technology for the Rocky Flats Fluidized Bed Unit
Authors:
W.R. Seeker, Ph.D.
Michele Boddy
Wyman Clark
Bruce Springsteen
G.R. Swanson, Ph.D. Desiree Chandler

Lawrence Livermore National Laboratory Draft (Future)

Evaluation and Control of $\mathrm{U}, \mathrm{Pu}$, and Am Volatiles in Mixed Waste

Oxidation Procedures

Author: $\quad$ O.H. Krikorian

Rockwell International RFP-3249 03/08/82

Rocky Flats Plant Fluidized Bed Incinerator
Authors:
L.J. Meile
F.G. Meyer
A.J. Johnson
D.L. Ziegler

Rockwell International RFP-3271 09/18/81

Incineration of Polychlorinated Biphenyl Using a Fluidized Bed Incinerator
Authors:
A.J. Johnson
F.G. Meyer
E.F. Lombardi 